This is a self-archived version of an original article. This version may differ from the original in pagination and typographic details.

Author(s): Bashiri Behmiri, Niaz; Ahmadi, Maryam; Junttila, Juha-Pekka; Manera, Matteo

Title: Financial Stress and Basis in Energy Markets

Year: 2021

Version: Accepted version (Final draft)

Copyright: (c) 2021 IAEE

Rights: In Copyright

Rights url: http://rightsstatements.org/page/InC/1.0/?language=en

Please cite the original version:

Bashiri Behmiri, N., Ahmadi, M., Junttila, J.-P., \& Manera, M. (2021). Financial Stress and Basis in Energy Markets. Energy Journal, 42(5), 67-87. https://doi.org/10.5547/01956574.42.5.nbeh 


\title{
Financial Stress and Basis in Energy Markets
}

\author{
Niaz Bashiri Behmiri ${ }^{a^{1}}$, Maryam Ahmadi ${ }^{b}$, Juha-Pekka Junttila ${ }^{\mathrm{c}}$, Matteo Manera ${ }^{\mathrm{d}}$
}

a University of Stavanger, UiS Business School, Norway, ${ }^{b}$ University of Milan-Bicocca, Italy, ${ }^{\mathrm{c}}$ University of Jyväskylä School of Business and Economics, Finland, ${ }^{\mathrm{d}}$ University of Milan-Bicocca and Fondazione Eni Enrico Mattei (FEEM), Italy

\begin{abstract}
We investigate the relationship between energy commodities bases, inventory and financial stress from 1994 to 2018 . We find that, from the 1998 Asian crisis the effect of financial stress on energy commodities bases gradually increased and from the 2008 crisis became positive, while the effect of inventory showed a gradual decline over time. The reactions of bases to changes in financial stress is nonlinear, as they are higher in the high financial stress periods. This is more profound in crude oil market than heating oil and natural gas. Moreover, the reactions of bases to the changes in inventory is nonlinear, as the reactions are lower when the inventory level is high confirming the theory of storage. We suggest that, in energy market, changes of inventory do not fully explain the variation of energy commodities bases, as the connection between commodity and financial markets increased during the recent years.
\end{abstract}

Keywords: Energy market bases, financial stress, inventories

JEL Classification: C51, G12, Q02, Q

\section{INTRODUCTION}

Increased financialization of commodity markets developed the association between financial and commodity markets. Therefore, besides the physical inventories, the changes in financial market conditions became an important influential factor on commodity futures prices. In this study, we suspect that the conventional inventory-based models, only measuring the relationship between the commodities basis and inventory under the theory of storage, are not sufficient to explain and predict the changes in the spread between spot and futures prices, the so-called basis. The goal of this study is to

\footnotetext{
${ }^{1}$ Corresponding author, email address: bashiri.niaz@gmail.com.
} 
understand the relationship between physical inventory, the US financial stress and the basis in the crude oil, heating oil and natural gas markets. Therefore, this study contributes into two groups of literature. The first group contains studies investigating the theory of storage, measuring the relationship between commodities bases and their physical inventories; the second group measures the association between financial condition and commodities futures prices.

The first group that investigates the relationship between commodities futures prices and their physical inventories has a long tradition in the theory of storage literature. Confirming the main implications of the theory of storage, a large number of studies have found a positive effect from a higher physical inventory on the commodity markets bases (See e.g., Cho and McDongall, 1990; Ng and Pirrong, 1994; Geman and Ohana, 2009; Gorton et al., 2012; Geman and Smith, 2013; Buyn, 2017). In crude oil market, Alquist and Kilian (2010), based on the analysis in Pindyck (1994, 2001), propose a theoretical model of the oil spot and futures markets that incorporates the convenience yield to explain the causes of the changes in basis, or equivalently, the difference in the variability of oil futures and spot prices. Their results show that, first, the difference between the spot and futures prices is equal to the convenience yield; and second, consistent with the findings of Kilian (2009), it is the uncertainty about shortfall of future supply relative to future demand, rather than supply or demand shocks themselves, that provides economic explanation for the fluctuations in the basis.

However, besides the physical inventory, the energy commodities bases can be affected by the financial condition. When financial stress increases, economic activity slows down, and this decreases the energy demand and their prices. Financial stress can affect economic activity through the bank lending channel, as higher financial stress decreases the available amounts of credits via changes in creditworthiness of borrowing businesses (Nazlioglu et al., 2015). On the other hand, increased financial stress will cause investors to change their portfolios and this will have an impact on energy prices. Consequently, changes in the energy prices can lead to a change in their basis, as we expect a higher change in the nearer futures prices than the more distant ones.

The relationship between financial condition and energy commodities bases increased during the recent years as participation of investors in commodity markets increased. After the 2008 equity market collapse, commodities, as an asset class, became very popular for portfolio diversification, due to their negative correlation with stock market (see, e.g., Gorton and Rouwenhorst, 2006). As a result, since 2003 the financialization of commodity markets grew and institutional investors 
rapidly built their positions in commodity futures markets (Basak and Pavlova, 2016; Byun, 2017). The US Commodity Futures Trading Commission (CFTC) shows that institutional holdings increased from $\$ 15$ billion in 2003 to over $\$ 200$ billion in 2008. With increased financialization of commodity markets, the correlations amongst the commodity futures markets, as well as between the equity and commodity futures markets increased. This significantly enhanced the information transmission between financial and commodity markets. Therefore, besides the physical inventories, the changes in financial market conditions became an important influential factor on commodity futures prices, especially after the 2008 global financial crisis.

In this study, we examine whether the relationship between the energy commodities bases, inventory and financial stress changed during the time span of this study. To better clarify our contribution, we discuss the group of literature that examines the association between financialization and commodities prices or financial condition and commodities prices. In this regard, for instance, Singleton (2014) focuses on the relationship between financialization and crude oil price, investigates the effect of growth of investors in commodity index funds and spread trades by hedge funds on excess returns of futures market contracts of crude oil. He concludes that after controlling for several factors, there is a significant effect from investors order flow on crude oil futures prices. The author argues that information frictions and the associated speculative activity cause the crude oil prices to drift away from their fundamental values. Ready (2018) focuses on the relationship between crude oil price and risk shocks in stock markets and finds that most of the crude oil price variation is explained by structural supply and demand shocks; however, there is also a role for risk shocks during and after the crisis period. Some more studies find a negative effect of higher stress in financial markets on commodity futures prices (see e.g., Sari et al., 2011; Chen et al., 2014). Moreover, a set of studies find a higher correlations between the stock and commodities futures markets during or after the 2008 crisis (see e.g., Tang and Xiong, 2011; Daskalaki and Skiadopoulos, 2011; Delatte and Lopez, 2013; Silvennoinen and Thorp, 2013; Nazlioglu et al., 2015; Cheng et al., 2015; Buyuksahin and Rob, 2014; Junttila et al., 2018). Buyuksahin and Rob (2014) argue that the increased correlation between commodity and equity markets is in part due to higher hedge funds' participation in futures markets. Among the studies concentrating the bases-financial markets rather than futures pricesfinancial markets relationship, Bailey and Chan (1993) examine the association between the commodity markets bases and 
financial markets and find the presence of common influences across them. They relate the strength of this correlation to the exposure of spot commodity prices to macroeconomic shocks. However, in a recent article, Byun (2017) finds that the crude oil price-inventory relationship is stable over time and the contribution of financial investors' participation to the crude oil market is weak.Therefore, majority of previous literature supports the presence of a relationship between financial markets and commodity futures prices. This causes the conventional basis-inventory models to be biased and misleads the energy market participants about their decision makings in this market. As Cho and McDougal (1990) and Serletis and Hullerna (1994) argue, the sign of the basis is known by energy market participants as a signal to decide whether to draw energy products out of storage or to store commodities. Therefore, the variation of the basis is an important factor in setting the efficient hedging strategy and improving profitability, and an incorrect perception of the basis behaviour can lead to unfavorable hedging results.

In this study, we focus on the effects of physical inventory and the US financial stress on the bases in energy commodities. We chose crude oil, natural gas and heating oil as the leading energy commodities. Based on the $\mathrm{CME}^{2}$ group data, these three commodities are the most actively traded energy commodities and crude oil is the most actively traded commodity in the world. Therefore, the correct prediction of their basis behavior is crucial for the traders in these markets. Moreover, it is important for companies of oil and gas exploration and production, oil refiners and marketing players, the airlines, and companies involved in petrochemicals.

Our study consists of different estimations. First, we estimate the effect of financial stress on the basis in energy commodities markets while controlling for inventory, before and after the 2008 global financial crisis. The results provide a primary insight on how the effects of inventory and financial stress on the energy commodities bases change after the 2008. However, there is a consensus in the literature that the responses of many economic factors to the financial stress shocks are nonlinear and depend on the level of financial stress in the economy (see e.g., Nazlioglu et al., 2015; Evgenidis and Tsagkanos, 2017; Aboura and Roye, 2017). To account for this phenomenon, we estimate the models including the quadratic terms of

\footnotetext{
${ }^{2}$ Chicago Mercantile Exchange.
} 
financial stress and inventory, as well as the interaction term between financial stress and inventory. The results enable us to understand the nonlinear dynamics of the energy commodities bases with respect to inventory and financial stress during the turbulent periods of the economy. Finally, we enrich our analysis by applying a very recent time varying parameter model developed by Bitto and Friuhwirth-Schnatter (2019), which provids several contributions to our study. The results visualize the gradual changes in the effects of inventory as well as financial stress on the energy commodities bases. Moreover, we observe the effects of financial stress on the bases before, during and after the turbulent periods of financial markets. We apply the end of period monthly data for the time span from January 1994 to December 2018.

Our results imply that, first, only after the 2008 financial crisis, there are evidences for a positive effect from the increasing level of financial stress on the energy market commodities bases. The effect of inventory remains positive during the whole time period; however, this positive effect gradually declines over time. Hence, after the 2008 collapse, the conventional inventory based models do not fully explain the energy market commodities bases. This result can be due to higher participation of financial investors, specifically hedge funds in commodity futures markets. The second major finding is that, the association between the energy commodities bases and the changes in financial stress is nonlinear, as the bases reactions are higher in the high financial stress periods. This is more profound in crude oil market than heating oil and natural gas. Moreover, the reactions of the energy commodities bases to the changes in the level of inventory is nonlinear, as the reactions is lower when the level of inventory is higher confirming the theory of storage. Third, there is an interaction effect between inventory and financial stress.

The paper is structured as follows. Section 2 describes the data. Section 3 provides the model, methods, results and discussion and section 4 ptovides concluding remarks.

\section{DATA DEFINITION AND SUMMARY STATISTICS \\ 2.1 Data Definition \\ 2.1.1 Interest-adjusted basis}

Fama and French $(1987,1988)$ in two seminal articles define the basis as:

$$
F(t, T)-S(t)=S(t) R(t, T)+W(t, T)-C(t, T)
$$


where $\mathrm{S}(\mathrm{t})$ is the spot price of commodity at time $t$ and $\mathrm{F}(\mathrm{t}, \mathrm{T})$ is the futures price at time $\mathrm{t}$ for delivery at time $\mathrm{T}$. The gain from purchasing the commodity at $\mathrm{t}$ for delivery at $\mathrm{T}, \mathrm{F}(\mathrm{t}, \mathrm{T})-\mathrm{S}(\mathrm{t})$, is identical to the risk free interest lose, $\mathrm{S}(\mathrm{t}) \mathrm{R}(\mathrm{t}, \mathrm{T})$, and marginal storage cost, $\mathrm{W}(\mathrm{t}, \mathrm{T})$, minus marginal convenience yield of inventory, $\mathrm{C}(\mathrm{t}, \mathrm{T})$, which is equivalent to:

$$
\frac{F(t, T)-S(t)}{S(t)}-R(t, T)=w(t, T)-c(t, T)
$$

where $\frac{F(t, T)-S(t)}{S(t)}$ is the basis, and the difference between the basis and risk free rate is the "interest-adjusted basis", $\mathrm{w}(\mathrm{t}, \mathrm{T})$ is the relative warehousing cost, and $\mathrm{c}(\mathrm{t}, \mathrm{T})$ is the relative convenience yield. The theory of storage assumes that the relative convenience yield decreases by increasing in inventory but at a decreasing rate, $\frac{\partial c}{\partial \mathrm{I}}<0$ and $\frac{\partial^{2} \mathrm{c}}{\partial^{2} \mathrm{I}}>0$.

We build the interest-adjusted basis for crude oil, heating oil and natural gas. This measure of basis has been widely applied in the literature (see, e.g., Fama and French, 1988; Gao and Wang, 2005; Geman and Ohana, 2009; Nikitopoulos et al., 2017). The interest-adjusted basis has the financial interpretation of the cost of carry, calculated as:

$$
i a b_{t T}=\frac{F(t, T)-F(t, 1)(1+r(t, T))}{F(t, 1)}
$$

where $i a b_{t T}$ is the interest-adjusted basis (adjusted-basis, henceforth). We calculate the 2, 4 and 12-month interestadjusted bases for crude oil, heating oil and natural gas. In computing the 2 -month adjusted-basis, the $\mathrm{F}(\mathrm{t}, 1)$ is the nearest future price, $\mathrm{F}(\mathrm{t}, \mathrm{T})$ is the 2-month future price and $\mathrm{r}(\mathrm{t}, \mathrm{T})$ is the risk free interest rate proxied by the annualized 1-month Treasury constant maturity rate divided by 12 . To calculate the 4 -month adjusted-basis, the $F(t, 1)$ is the nearest future price, $\mathrm{F}(\mathrm{t}, \mathrm{T})$ is the 4-month future price and $\mathrm{r}(\mathrm{t}, \mathrm{T})$ is the risk free interest rate proxied by the annualized 3-month Treasury constant maturity rate divided by 4 . In calculating the 12 -month adjusted-basis, the $F(t, 1)$ is the nearest future price, $F(t, T)$ is the 12 month future price and $\mathrm{r}(\mathrm{t}, \mathrm{T})$ is the risk free interest rate proxied by the annualized 12-month Treasury constant maturity rate ${ }^{3}$.

\footnotetext{
${ }^{3}$ Pindyck (1994) states that spot prices do not necessarily reflect the actual transactions of the day and cannot be matched with futures prices. Moreover, spot markets of many commodities are not liquid in the same way as their futures markets. For these reasons, following the literature (see e.g., Symeonidis et al., 2012; Geman and Smith, 2013) we apply the nearest future price as a proxy of the spot price.
} 
The continuous closing futures prices are light sweet Cushing Oklahoma crude oil, the No. 2 heating oil New York Harbor, and the natural gas Henry Hub, traded on the New York Mercantile Exchange (NYMEX) ${ }^{4}$. We use the end of period monthly data for the time span from January 1994 to December 2018. The sources of futures prices and the interest rate data are the NYMEX and the Federal Reserve Bank of St. Louis Economic Database (FRED), respectively.

\subsubsection{Inventory measures}

To explain the crude oil and heating oil adjusted-bases, we apply the total OECD petroleum inventory data measured in million barrels, which is a global index for petroleum inventory. To explain the natural gas adjusted-basis, we apply the lower 48 states natural gas working underground storage in billion cubic feet. We collecte the inventory data from the Energy Information Administration (EIA) in end of period monthly frequency from January 1994 to December 2018.

\subsubsection{Financial stress index}

Financial stress is a situation where there is a disruption to the usual functioning of financial markets and no two periods of financial stress have the same characteristics. However, as Hakkio and Keeton (2009) state, economists link certain key occurrences in financial markets with financial stress and the importance of these occurrences can be different from one period of financial stress to another. Therefore, there is no consensus on a single definition for financial stress and this has led to developing various financial stress indexes. Previous studies apply different financial stress indexes to explain the association between energy prices and financial stress. For example, Wan and Wei-Kao (2015) study the nonlinear relationships between crude oil price and financial variables. They proxy the financial stress condition by the National Financial Conditions Index, which is supplied by the Chicago Fed and provides a comprehensive update on financial

\footnotetext{
${ }^{4}$ For crude oil, each contract expires on the third business day prior to the $25^{\text {th }}$ calendar day of the month preceding the delivery month. If the $25^{\text {th }}$ calendar day of the month is a non-business day, trading ceases on the third business day prior to the business day preceding the $25^{\text {th }}$ calendar day. After a contract expires, contract 1 for the remainder of that calendar month is the second following month. For heating oil, each contract expires on the last business day of the month preceding the delivery month. Thus, the delivery month for contract 1 is the calendar month following the trade date. For natural gas, the contracts expire three business days prior to the first calendar day of the delivery month. Thus, the delivery month for contract 1 is the calendar month following the trade date.
} 
conditions in the US market. Also, they apply the spread between Moody's BAA and AAA corporate bonds yields as the second measure of financial stress. They find a nonlinear relationship between oil and financial variables meaning that shocks in the high stress regime have larger and longer effects than shocks in the normal regime. Nazlioglu et al. (2015) assess the volatility transmission between crude oil price and the Federal Reserve Bank of St.Louis Financial Stress Index. They find a risk transfer mechanism from crude oil price to financial stress before the 2008 financial crisis and a reverse causality from financial stress to crude oil prices after the crisis. Reboredo and Uddin (2016) investigate the co-movement and causality between financial stress, defined by VIX and the Federal Reserve Bank of St.Louis Financial Stress Index, and energy and metal commodities. Their results support the influence of financial stress on the intermediate and upper quantiles of commodity returns; however, no evidence is found for co-movement. Das et al. (2018) examine the relationship between stocks, gold, and crude oil with financial stress, considering the Federal Reserve Bank of St.Louis Financial Stress Index. They find a bilateral causality in mean and variance for gold and crude oil with respect to financial stress. Qadan and IdilbiBayaa (2020) examine the link between crude oil prices, risk appetite and economic uncertainty, decompose VIX into economic uncertainty and implied risk appetite components. They find that the role of risk appetite to crude oil prices became significant since the mid-2000s. Finally, Gkillas et al. (2020) analyze the role of financial stress in forecasting crude oil price volatility using the Office of Financial Research (OFR) Financial Stress Indexes and find that indexes of financial stress help to improve forecasting performance of crude oil price volatility.

In this study, we apply the Federal Reserve Bank of St. Louis Financial Stress Index (STLFSI) to proxy the US financial condition. The variables in constructing the STLFSI come from interest rates (both government and corporate bond rates), yield spreads and other indicators, including exchange market and inflationary pressure. The latest variables include J.P.Morgan Emerging Markets bond index, VIX, Merrill Lunch bond market volatility index, 10-year nominal Treasury yield minus 10-year Treasury inflation protected security yield and Vanguard Financials Exchange-traded funds. The average value of STLFSI at zero implies normal financial market conditions, while the negative value shows the below average and the positive value represents the above average financial stress conditions. We collect the STLFSI data from the FRED as the end of period monthly observations from January 1994 to December 2018. 


\subsection{Summary Statistics}

To account for seasonality, we follow the Geman and Ohana (2009) and Symeonidis et al. (2012) method. We test for the presence of seasonality by regressing each variable on a constant, a time trend and monthly dummy variables. Then, we use the $t$-statistics of the time variable to examine the presence of time trend and a joint significance $F$ test on monthly dummy variables to examine the presence of seasonality effect. Adjustment for trend and seasonality is based on the significance of the $t$ and $F$-statistics, respectively. In the $F$ test, the null hypothesis is that the coefficients of all monthly dummies are jointly significant. We find that, both time trend and monthly dummies are significant for the OECD petroleum and the US natural gas inventories, and the 2 and 4-month adjusted-bases of heating oil and natural gas. However, the monthly dummies are not jointly significant for other variables and there is no periodicity in their behavior. The residuals that we obtain from these regressions are the de-trended and de-seasonalized series of observations ${ }^{5}$. Then, the Augmented Dickey Fuller (1979) and the Lee and Strazicich (2003) minimum LM unit root tests are performed on the de-trended and deseasonalized data to test for their stationarity properties. Table 1 reports the descriptive statistics and the unit root tests results.

[Table 1 about here]

We find evidences to support stationarity of all variables for the full sample and for the sub-samples of before and after the 2008 crisis. The graphs for the original as well as the de-trended and de-seasonalized data are illustrated in Figures 1a-1b.

[Figures 1a-1b about here]

\section{METHODS, RESULTS AND DISCUSSION}

\subsection{Primary Estimations}

\subsubsection{The primary estimations models and method}

${ }^{5}$ As an alternative method to obtain unit free inventory data that has no trend, following Gorton et al. (2012), we calculated the normalized inventory levels. We use the Hodrick-Prescott filter to generate the normal inventory levels. The ratio of actual inventory divided by the normal inventory level is the normalized inventory level. Then we de-seasonalized these variables. The results are robust in terms of statistical significance and the conclusion. 
We regress the 2, 4 and 12-month adjusted-bases ( $i a b_{2}, i a b_{4}$ and $i a b_{12}$, respectively) of each commodity on the Federal Reserve Bank of St. Louis' Financial Stress Index (STLFSI) and the level of inventories:

$$
i a b_{t T}=\alpha_{0}+\alpha_{1} \text { STLFSI }_{t}+\alpha_{2} \text { Inventory }_{t}+u_{t}
$$

Also, we regress the 2, 4 and 12-month adjusted-bases on the STLFSI, inventory, the squared terms of STLFSI and inventory and the interaction term between the STLFSI and inventory (Interact) to capture the nonlinearity of relationship between the adjusted-bases, financial stress and inventory:

$$
i a b_{t T}=\alpha_{0}+\alpha_{1} \text { STLFSI }_{t}+\alpha_{2} \text { STLFSI }^{2}+\alpha_{3} \text { Inventory }_{t}+\alpha_{4} \text { Inventory }^{2}+\alpha_{5} \text { Interact }+u_{t}
$$

The Ordinary Least Squares (OLS) method is applied to estimate models 4 and 5.

\subsubsection{The primary estimation results}

The estimation results of equation 4, including coefficients, standardized coefficients and the Newey-West standard errors are are reported in Table $2^{67}$. The estimations are performed for the sub-samples of before and after the 2008 crisis. The time period of before the crisis includes data from 1994M1- 2006M12 and after the crisis covers from 2009M1-2018M12 ${ }^{8}$.

[Table 2 about here]

At Table 2, first, the coefficients associated to inventory before and after the crisis show that, the inventory levels have statistically significant and positive effect on the adjusted-bases; however, the magnitude of these positive effects becomes

\footnotetext{
${ }^{6}$ We estimate equation 4 using the alternative financial stress indexes, including the Kansas City Financial Stress Index and the VIX. The results are reported in Online Appendix, Appendix 1, Tables 1a-1b.

${ }^{7}$ We estimate equation 4 using the alternative inventory measures, including the US total petroleum products and the US crude oil inventories to explain the crude oil and heating oil adjusted-bases. The results are reported in Online Appendix, Appendix 2, Table 2.

${ }^{8}$ The crisis period from 2007M01-2008M12 is excluded from the estimation, as during the crisis the adjusted-basis might be subject to irregular behaviors. However, we perform several robustness checks considering different time splits. Equation 4 is estimated considering: a) before the crisis from 1994M012007M06 and after the crisis from 2009M06-2018 M12, b) before the crisis from 1994M01-2007M12 and after the crisis from 2008M01-2018M12, without excluding the crisis period, and finally c) before increasing financialization in commodity markets from 1994M01-2004M12, and after the surge in financialization from 2005M01-2018M12. The results are reported in Online Appendix, Appendix 3, Tables 3a-3c.
} 
smaller after the 2008 crisis. This applies to the adjusted-bases of the three commodities with different maturities. Second, the coefficients associated to financial stress show that, before the 2008 crisis, the results do not reveal a statistically significant effect from financial stress condition; however, after the crisis, the effect of stress becomes significant with a positive effect, i.e., the adjusted-bases react positively to the increasing level of stress in the financial markets. This applies to the three commodities and different maturities of adjusted-bases. Third, the standardized coefficients reveal that, for the three commodities, the longer the adjusted-basis maturity is, the magnitudes of inventory and financial market stress standardized coefficients are bigger. The exception is the crude oil adjusted-basis, in which financial stress shows a bigger effect on shorter maturity adjusted-basis of crude oil. Fourth, the standardized coefficients show that, after the 2008 crisis, the importance of changes in financial stress condition on explanting the crude oil adjusted-basis behavior is higher than inventory, and this result is robust for different maturities of adjusted-basis; however, for heating oil and natural gas, despite the fact that the role of financial stress condition becomes significant after the 2008 crisis, nevertheless inventory remains a more important factor than financial stress condition in explaining their adjusted-bases behavior. This stresses that the crude oil market is more connected to the financial markets compared to the heating oil and natural gas markets.

We draw the main conclusion that, the magnitudes of changes in energy market commodities adjusted-bases with respect to the changes in US financial stress and the level of inventories have changed after the 2008 crisis. The association between the financial markets and commodities markets futures is well documented in the literature, and we expect that a higher stress in the US financial market lowers energy futures prices. For instance, Sari et al. (2011) find that a higher VIX significantly dampens the oil futures price and Nazlioglu et al. (2015) conclude that there is a volatility spillover between the oil futures market and financial stress. If the financial stress shock is as high to be transmitted to commodities prices, it is more likely that the spot or near futures prices declines more than the distant futures agreement prices, as it is expected that in the future, the economy will adjust based on changes in the commodity market prices. Therefore, this difference in the reduction of prices with different maturities makes the adjusted-basis to increase. However, this effect is only observed after the 2008 crisis. 
Furthermore, the estimation results of equation 5 , including coefficients, standardized coefficients and the NeweyWest standard errors for the full sample from 1994M01-2018M12, are reported in Table $3^{9}$.

[Table 3 about here]

The objective of this estimation is to understand the nonlinear relationship between the adjusted-basis and the predictors. First, we find that, for crude oil and heating oil, the coefficients related to inventory is positive and significant while the coefficients related to squared term of inventory is negative and significant. This applies to all maturities of the adjusted-basis. This result validates the theory of storage in these two markets for shorter and longer maturity adjusted-bases indicating that, with increasing inventory the adjusted-basis would increase but with a decreasing rate. However, for natural gas, the squared term of inventory is positive and significant only for the 12-month adjusted-basis. Second, the coefficients associated with financial stress show that, for crude oil, the squared term of financial stress is positive and significant for different maturities of the adjusted-basis. For heating oil, the squared term of financial stress is positive and significant only for the 12-month adjusted-basis, and for natural gas, we do not find any significant effect from the squared term of financial stress. Focusing on the interaction effect between inventory and financial stress, we find that for the three commodities, the interaction effect is positive and significant, and this applies for all maturities of the adjusted-basis.

We perform four joint significance tests between, (a) financial stress and the squared term of financial stress, (b) inventory and the squared term of inventory, (c) financial stress, the squared term of financial stress and the interaction term between financial stress and inventory, (d) inventory, the squared term of inventory and the interaction term between financial stress and inventory. We find that, for crude oil, all the joint significance tests are statistically significant, for heating oil, (a) is significant only for the 12-month adjusted-basis; however, (b), (c) and (d) are significant for all maturities of the adjustedbasis. For natural gas, except (c) for the 2-month adjusted-basis, the other tests are significant for all maturities of the adjustedbasis.

\footnotetext{
${ }^{9}$ We estimate equation 5 using the alternative financial stress indexes, including the Kansas City Financial Stress Index and the VIX. The results are reported in Online Appendix, Appendix 4, Tables 4a-4b.
} 
In summary, the first main conclusion is that, for crude oil, the effect of financial stress on 2, 4 and 12-month adjustedbases is nonlinear in favor of high financial stress periods. This means that a higher financial stress would increase the adjusted-bases in crude oil market and this effect is stronger during turbulent periods of financial stress; however, for heating oil, the evidence of nonlinearity in favor of turbulent periods is supported only for the long term maturity (12-month) adjustedbasis, and for natural gas, there is no strong evidence to support the nonlinearity of responses to financial stress conditions. The second main finding is that, the reactions of crude oil and heating oil adjusted-bases to the changes of inventory is nonlinear, as the reactions are lower when the level of inventory is high (theory of storage). Finally, there is an interaction effect between inventory and financial stress.

\subsection{The Time Varying Parameter Model Estimations}

In macroeconomics and finance, the time varying parameter (TVP) models are popular as in most cases, the effect of certain predictors on dependent variables changes over time (Primiceri, 2005; Dangl and Halling, 2012; Belmonte et al., 2014). Our primary regression findings also show that the impact of inventory and financial stress on the adjusted-bases in energy markets is not constant over time and the significance of effects changes by changing the time span. Since many times only a small group of the parameters are time-varying, despite being able to reproduce noticeable features of the data, the time varying parameter models show a serious risk of overfitting (Bitto et al., 2019). The risk of overfitting increases with increasing the number of coefficients, as many coefficients might be actually constant over time and allowing static coefficients to vary over time leads to a significant loss of statistical efficiency compared to a model with constant apriori coefficients (Bitto and Fruhwirth-Schnatter, 2019). To deal with this problem, several researchers developed methods that distinguish between static and time varying parameters in time varying parameter models. However, recognizing fixed coefficients in a time varying parameter model leads to a variance selection problem. Frühwirth-Schnatter and Wagner (2010) recast the problem of variance selection and shrinkage in terms of variable selection, thus allowing any tool used to this end in multiple regression models to be used to perform selection or shrinkage of variances. The authors show a key contribution, as they introduce the non-centered parametrization of time varying parameter models. This gives the possibility to extend shrinkage priors from the standard regression analysis to the more general framework to define a sparse state space model (Bitto et al., 2019). 
In a very recent paper, Bitto and Fruhwirth-Schnatter (2019) develop the sparse state space models with a new continuous shrinkage prior for process variances. The authors introduce the normal gamma prior in the non-centered parameterization and state that this leads to a double gamma prior for the process variances. Bitto et al. (2019) assert that a second shrinkage prior allows to shrink static coefficients to insignificant coefficient over the entire time period, which enables us to differentiate between time-varying coefficients, statistic significant coefficients and insignificant coefficients.

\subsubsection{The time varying parameter method}

The state space form of a time varying parameter model is:

$$
\begin{aligned}
& y_{t}=x_{t} \beta_{t}+\epsilon_{t}, \quad \epsilon_{t} \sim N\left(0, \sigma_{t}^{2}\right), \\
& \beta_{t}=\beta_{t-1}+w_{t}, \quad w_{t} \sim N_{d}(0, Q) .
\end{aligned}
$$

where $t=1, \ldots, T, y_{t}$ is the univariate dependent variable, and $x_{t}$ is a vector of $d$ number of regressors at time $t$, including the intercept. In this study, $y_{t}$ is the interest-adjusted basis and $x_{t}$ is a vector of 2 regressors that are financial stress and inventory. It is assumed that $Q=\operatorname{Diag}\left(\theta_{1}, \ldots \theta_{d}\right)$ is a diagonal matrix that shows the conditional independence of the state innovations. Moreover, it is assumed that the initial value tracks a normal distribution, i.e., $\beta_{0} \sim N_{d}(\beta, Q)$, in which the initial mean is $\beta=\left(\beta_{1}, \ldots, \beta_{d}\right)$. Bitto and Fruhwirth-Schnatter (2019) rewrite model 6 in the non-centered parametrization as:

$$
\begin{gathered}
y_{t}=x_{t} \beta+x_{t} \operatorname{Diag}\left(\sqrt{\theta_{1}}, \ldots, \sqrt{\theta_{d}}\right) \tilde{\beta}_{t}+\epsilon_{t}, \quad \epsilon_{t} \sim N\left(0, \sigma_{t}^{2}\right), \\
\tilde{\beta}_{t}=\tilde{\beta}_{t-1}+\tilde{u}_{t}, \quad \tilde{u}_{t} \sim N_{d}\left(0, I_{d}\right) .
\end{gathered}
$$

where $\widetilde{\beta}_{0} \sim N_{d}\left(0, I_{d}\right)$, and $I_{d}$ is the identity matrix with $d$ dimension. Moreover, we model the observation error via stochastic volatility specification to account for heteroskedasticity. The stochastic volatility model captures some part of the variability in the error term and would avoid spurious variations in the time varying coefficients (Nakajima, 2011; Sims, 2001). In this case, the $h_{t}=\log \sigma_{t}^{2}$ follows a stationary distribution of the AR(1) process (Jacquier et al., 1994; Kastner and Frühwirth-Schnatter, 2014; Kastner, 2016) as:

$$
h_{t} \mid h_{t-1}, \mu, \phi, \sigma_{\eta}^{2} \sim N\left(\mu+\phi\left(h_{t-1}-\mu\right), \sigma_{\eta}^{2}\right)
$$

where the initial state follows $h_{0} \sim N\left(\mu, \sigma_{\eta}^{2} /\left(1-\phi^{2}\right)\right)$. 
Bitto and Fruhwirth-Schnatter (2019) place conditionally independent normal-gamma priors developed by Griffin and Brown (2010) on innovations standard deviations, $\sqrt{\theta_{j}}$, and on means of initial value, $\beta_{j}$, where $j=1, \ldots, d$. The authors state that this prior can be introduced as a conditionally normal distribution, with the component specific variance following a gamma distribution, which is:

$$
\begin{array}{ll}
\sqrt{\theta_{j}} \mid \xi_{j}^{2} \sim N\left(0, \xi_{j}^{2}\right), & \xi_{j}^{2} \mid a^{\xi}, k^{2} \sim \mathrm{g}\left(a^{\xi}, \frac{a^{\xi} k^{2}}{2}\right), \\
\beta_{j} \mid \tau_{j}^{2} \sim N\left(0, \tau_{j}^{2}\right), & \tau_{j}^{2} \mid a^{\tau}, \lambda^{2} \sim \mathrm{g}\left(a^{\tau}, \frac{a^{\tau} \lambda^{2}}{2}\right) .
\end{array}
$$

The prior variances $\xi_{j}^{2}$ and $\tau_{j}^{2}$ are the local shrinkage parameters, as they control the intensity that each individual parameter $\sqrt{\theta_{j}}$ and $\beta_{j}$ is dragged toward zero. However, the parameters $k^{2}$ and $\lambda^{2}$ are squared global shrinkage parameters, as they specify how intensely the parameters are moved toward zero. Since the $\mathrm{E}\left(\theta_{j} \mid a^{\xi}, k^{2}\right)=\frac{2}{k^{2}}$ and $\mathrm{E}\left(\beta_{j}^{2} \mid a^{\tau}, \lambda^{2}\right)=\frac{2}{\lambda^{2}}$, with increasing $k^{2}$ and $\lambda^{2}$, their effects increase. Finally, $a^{\xi}$ and $a^{\tau}$ are shrinkage adaption parameters and as they decrease, more mass will be placed around zero and jointly more mass is put on sparse specifications of the model (Bitto et al., 2019).

The $k^{2}, \lambda^{2}, a^{\xi}$ and $a^{\tau}$ can be learn from the data through appropriate prior distributions or the prior setup can be controlled by specifying all or a subset of the parameters. This means that, we can change the hyperparameters, fixing values of the global shrinkage parameters $\left(k^{2}, \lambda^{2}\right)$ and the shrinkage adoption parameters $\left(a^{\xi}, a^{\tau}\right)$. There are two benefits for using the fixed values; first, desired degrees of sparsity and global shrinkage can be obtained; second, interesting special cases arise from setting certain values of hyperparameters. For instance, setting local adoption parameters $\left(a^{\xi}, a^{\tau}\right)$ equal to one leads to a Bayesian Lasso (Park and Casella, 2008) prior on the $\sqrt{\theta_{j}}$ and $\beta_{j}$, respectively (Bitto et al., 2019).

\subsubsection{The time varying parameter estimation results}

We estimate three time varying parameter models. In the first estimation, the dependent variable is the crude oil 12month adjusted-basis and explanatory variables are the OECD petroleum inventory and the Federal Reserve Bank of St. Louis’ Financial Stress Index (STLFSI), the results are reported in Figure 2a. In the second one, the dependent variable is the heating oil 12-month adjusted-basis and explanatories are the OECD petroleum inventory and the STLFSI, the results are reported in 
Figure $2 \mathrm{~b}$. In the third one, the dependent variable is the natural gas 12-month adjusted-basis and explanatories are the US natural gas inventory and the STLFSI, the results are reported in Figure $2 c^{10}$.

To estimate the models, we apply the Bayesian Lasso prior, in which the shrinkage adoption parameters of $a^{\xi}$ (shrinkage on $\sqrt{\theta_{j}}$ ) and $a^{\tau}$ (shrinkage on $\beta_{j}$ ) are fixed at 1 , and the global shrinkage parameters of $k^{2}$ (shrinkage on $\sqrt{\theta_{j}}$ ) and $\lambda^{2}$ (shrinkage on $\beta_{j}$ ) are fixed at 100 . Moreover, the errors are modeled through stochastic volatility.

Figures $2 \mathrm{a}-2 \mathrm{c}$ show that, for the three commodities, first, the parameters associated with inventory and financial stress are time-varying; second, the parameters associated with inventory are decreasing over time; third, the parameters related to the financial stress are increasing over time.

Even though the coefficients associated to inventory have a decreasing pattern over time for the three commodities, but during the whole time period the sign stays positive and mostly statistically significant. It is visible that the inventory coefficients for crude oil, heating oil and natural gas start to decline from the Asian financial crisis period around years 1997$1998^{11}$. However, a more drastic change happens to the coefficients related to financial stress, as their sign shifts from negative to positive during the 2008 global financial crisis. For the three commodities, the financial stress coefficients started to show a gradual increase around the 1998 Asian financial crisis and has a negative sign, that for some periods it is statistically significant for crude oil and heating oil and it never showed any evidence of significance for natural gas. However, the direction of effect changed around the year 2008, as the financial stress coefficients show a positive and statistically significant jump during the 2008 financial crisis period for the three commodities; however, the jump is sharper for crude oil compared

\footnotetext{
${ }^{10}$ We perform the time varying parameter estimations using the alternative financial stress indexes, including the Kansas City Financial Stress Index and the VIX. The results are reported in Online Appendix., Appendix 5, Figures 1a-1c and Figures 2a-2c.

${ }^{11}$ A specific argument about crude oil is that, there is evidence for the insignificant coefficients related to inventory from the year 2012 and afterwards. This could be mainly due to the excess supply of light sweet crude oil, coming from an unexpected increase in the US shale oil production that started in the mid2000s, which was largely concentrated in small geographic regions, where the WTI price is measured. (Kilian, 2016). As the consequence, from the year 2012 to 2015, there was a sharp increase in the US crude oil production, and it remained stable afterwards. This coincides with a period of a statistically significant upward shift in financial stress coefficient for crude oil.
} 
to heating oil and natural gas. Finally, after the period of financial crisis, the positive coefficients decreased compared to the crisis period but they continue to have a positive sign. This means that the reaction of adjusted-bases to the changes in financial stress condition is nonlinear, as the coefficients are bigger during the stressful period. The same conclusions are achieved from primary estimations of equation 5 .

\subsection{Discussion of the Results}

Summing up the primary estimations and the time varying model results, we can draw four conclusions. First, only after the 2008 financial crisis, there are evidences for a positive effect from the increasing level of financial stress on the energy market commodities adjusted-bases. However, the positive effect of inventory decreases during the time period of this study. Hence, the conventional inventory based models are not enough to explain the energy market commodities adjustedbases. The association between energy commodities adjusted-bases, inventory and financial stress changed gradually during the time span of this study, starting from the 1998 Asian crisis, and it did not happen all of a sudden. However, the 2008 financial crisis triggered the association between financial stress and adjusted-bases, as the effects became positive and statistically significant from 2008. Therefore, higher participation of financial investors had a significant role on increasing the association between futures markets and financial stress; as based on the CFTC report, the institutional holdings increased from \$15 billion in 2003 to over \$200 billion in 2008 and remained high afterwards.

Our results mirror some of the previous studies that emphasize the commodity price or futures curve-financialization relationship. To understand the 2008 oil price boom and bust, for example Singleton (2014) focuses on the role of investor flows and finds that, there is a significant effect from investor flows on the oil futures prices, and that hedge fund trading in spread positions in futures affects the shape of the oil market term structure. In addition, to understand the crude oil futures risk premia over time, Hamilton and $\mathrm{Wu}$ (2014) consider financial investments and conclude that since 2005, index fund investing has become more important compared to commercial hedging. These authors relate this change to the increased rate of participation of financial investors in crude oil futures markets. Moreover, to realize the reason behind the extended period of positive oil futures curve that started since 2008, Nikitopoulos et al. (2017) argue that the conventional inventory based explanation is not sufficient to explain the dynamics of oil futures curve anymore. The authors propose that the options market implied volatility has predictive power on the oil futures spread. However, Byun (2017) shows that there is a stable 
relationship between crude oil price and inventory over time and concludes that financial investors' participation role to the crude oil market is weak. These different results can be due to different time span of study, methodology and model.

Moreover, our results echo the results from studies that have more precise focus on the commodity-equity markets comovement patterns. In this regard, Mollick and Assefa (2013) find changes in correlations between stock and oil prices for three sub-samples of before, within and after the 2008 financial crisis. The insignificant correlations before and within the January 2008-June 2009 period turn to be positive and statistically significant after the 2008 crisis. Furthermore, Junttila et al. (2018) show that after the 2008 crisis, the correlation between crude oil and US equity returns has been continuously higher than before the crisis. Tang and Xiong (2011) reveal that after 2004, the Goldman Sachs Commodity Index (GSCI) and Dow Jones (DJ)-AIJ indexes of agricultural commodities show higher responses to shocks in crude oil prices, world equity index and changes in the US dollar exchange rate. On the other hand, Buyuksahin and Robe (2014) show that variations in the commodity futures open interest contribute in long-term fluctuations in commodity-equity return co-movements prediction. The authors relate the higher commodity-equity co-movement to higher hedge funds participation in futures markets.

Our second major finding is that, the association between the adjusted-bases in crude oil, heating oil and natural gas with the changes in financial stress is nonlinear, as the adjusted-bases reactions to financial stress are higher in the high financial stress periods, this is specifically visible in the time varying parameters during the 2008 crisis, and is more profound in crude oil market than heating oil and natural gas. This result also resembles some previous findings that the effect of financial shocks on economic variables is nonlinear, depending on whether the economy is in a high or a normal financial stress period (see e.g., Nazlioglu et al., 2015; Evgenidis and Tsagkanos, 2017; Aboura and Roye, 2017; Alessandri and Mumtaz, 2019).

The third major finding is that, for crude oil and heating oil the reactions of the adjusted-bases to the changes in the level of inventory is nonlinear, as the reactions is lower when the level of inventory is high, which is in line with the theory of storage. Finally, fourth, there is an interaction effect between inventory and financial stress, meaning that the strength of the effect of financial stress (inventory) on the adjusted bases depends on the level of inventory (financial stress). 
In general, we find that after the 2008 crisis, the effect of financial stress on the adjusted-basis of crude oil is bigger than heating oil and natural gas. Besides the difference in financialization of these commodities, it is well known that despite the increasing emergence of the role of all various forms of renewable energy sources; crude oil is still significantly relevant to macro development, as it is widely used in many production processes. Hence, the financial market stress seems highly relevant for the basis fluctuations of crude oil market. However, after the 2008 crisis, the effect of inventory on adjusted-basis of natural gas is bigger than crude oil and heating oil, as natural gas is very relevant in electricity production as the least carbon-intensive of all fossil fuels. This result suggests the fact that its role might also have been increasing due to the increasing capacity and utilization of renewable energy sources after the global financial crisis years in e.g. electricity production $^{12}$.

\section{CONCLUSION}

The main goal of this study is to examine the role of stress in the US financial markets on the interest-adjusted basis values in the crude oil, heating oil and natural gas markets, during the time span from 1994 to 2018. First, we regress interestadjusted basis of each commodity on the Federal Reserve Bank of St. Louis' Financial Stress Index, and the level of physical inventories. Moreover, we regress the interest-adjusted bases on the financial stress, inventory, the quadratic terms of financial stress and inventory and the interaction term between financial stress and inventory, to capture the nonlinearity of relationship between the interest-adjusted bases, financial stress and inventory. Second, we apply the Bitto and Fruhwirth-Schnatter (2019) time-varying parameter method to measure the gradual changes in parameters of energy commodities interest-adjusted basis with respect to changes in inventory and financial stress.

\footnotetext{
${ }^{12}$ We apply Bitto and Fri.ihwirth-Schnatter (2019) approach to estimate the time varying parameter models with using the Federal Reserve Bank of Kansas City Financial Stress Index (KCFSI) and the VIX, reported in Online Appendix, Appendix 5. The time varying coefficients of KCFSI show robust results compared to the STLFSI. The time varying coefficients of VIX show that, for crude oil and heating, we come to the same conclusion as the STLFSI; however, for natural gas, although the coefficients are time varying but we do not find an increasing pattern over time and it is statistically insignificant both before and after the 2008 crisis. Therefore, natural gas is less connected to the stock markets compared to crude oil and heating oil and this confirms our primary results.
} 
The results imply that, only after the 2008 financial crisis, there are evidences for a positive effect from the increasing level of financial stress on the energy market commodities interest-adjusted bases. The effect of inventory remains positive during the whole time period; however, this positive effect gradually declines over time. Hence, after the 2008 collapse, the conventional inventory based models are not sufficient to explain the energy market commodities bases. These results can be due to higher participation of financial investors, specifically hedge funds in commodity futures markets. Moreover, the association between the energy commodities interest-adjusted bases with the changes in financial stress is nonlinear, as the bases reactions to the financial stress are higher in the high financial stress periods. This is more profound in crude oil market than heating oil and natural gas. Moreover, the reactions of the energy commodities interest-adjusted bases to the changes in the level of inventory is nonlinear, as the reactions is lower when the level of inventory is high confirming the theory of storage. Finally, there is an interaction effect between inventory and financial stress, which shows that the strength of the effect of inventory (financial stress) on the energy commodities adjusted basis depends on the level of financial stress (inventory).

Therefore, after the 2008 crisis, inventories have not been the only driver behind the changes in energy commodities markets bases, as with the growing financial liberalization of commodities, financial market conditions have become an important factor in explaining the behavior of bases in energy markets. This is more evident during higher turbulence in the financial markets. Therefore, variations of the spread between spot and futures prices are not only a signal of scarcity or abundance of the commodities in question. These results are useful for all the energy markets participants, the financial market traders, refiners and other energy users who consider the energy bases variations when making their decisions. In addition, the results are important to policy makers for the part of financial market related shock effects on the real economy, i.e., the energy commodity markets in this case.

\section{REFERENCES}

Aboura, D., Roye, B. (2017). "Financial stress and economic dynamics: The case of France." International Economics 149: 57-73.

Alessandri, P., Mumtaz, H. (2019). "Financial regimes and uncertainty shocks." Journal of Monetary Economics 101: 31-46.

Alquist, R., Kilian, L. (2010). "What do we learn from the price of crude oil futures?" Journal of Applied Econometrics 25(4): 539-573.

Bailey, W., Chan, K.C. (1993). "Macroeconomic influences and the variability of the commodity futures basis." The Journal of Finance 48(2): 555-573. 
Basak, S., Pavlova, A. (2016). "A model of financialization of commodities." The Journal of Finance 71(4): 1511-1556.

Belmonte, M.A.G., Koop, G., Korobolis, D. (2014). "Hierarchical shrinkage in time-varying parameter models." Journal of Forecasting 33: 80-94.

Bitto, A., Cadonna, A., Frühwirth-Schnatter, S., Knaus, P. (2019). "Shrinkage in the time-varying parameter model framework using the R package shrinkTVP." Cornell University Working Paper.

Bitto, A., Friuhwirth-Schnatter, S. (2019). "Achieving shrinkage in a time-varying parameter model framework." Journal of Econometrics 210 : 75 - 97.

Buyuksahin, B., Robe, M.A. (2014). "Speculators, commodities and cross-market linkages." Journal of International Money and Finance 42: 38-70.

Byun, S. (2017). "Speculation in commodity futures markets, inventories and the price of crude oil." The Energy Journal 38(5): 1-36.

Chen, W., Hamori, S., Kinkyo, T. (2014). "Macroeconomic impacts of oil prices and underlying financial shocks." Journal of International Financial Markets, Institutions and Money 29: 1-12.

Cheng, I., Kirilenko, A., Xiong, W. (2015). "Convective risk flows in commodity futures markets." Review of Finance 19: 1733-1781.

Cho, D.W., McDongall, G.S. (1990). "The supply of storage in energy futures markets." The Journal of Futures Markets 10: 611-621.

Dangl. T., Halling, M. (2012). "Predictive regressions with time-varying coefficients." Journal of Financial Economics 106: 157-181.

Das, D., Kumar, S.B., Tiwari, A.K., Shahbaz, M., M.Hashim, H. (2018). "On the relationship of gold, crude oil, stocks with financial stress: A causality-inquantiles approach." Finance Research Letters 27: 169-174.

Daskalaki, C., Skiadopoulos, G. (2011). "Should investors include commodities in their portfolios after all?" Journal of Banking and Finance 35(10): 26062626.

Delatte, A., Lopez, C. (2013). "Commodity and equity markets: Some stylized facts from a copula approach." Journal of Banking and Finance 37(12): 53465356.

Dickey, D.A., Fuller, W.A. (1979). "Distribution of the estimators for autoregressive time series with a Unit Root." Journal of American Statistical association 74: $427-431$.

Evgenidis, A., Tsagkanos, A. (2017). "Asymmetric effects of the international transmission of US financial stress. A threshold-VAR approach." International Review of Financial Analysis 51: 69-81.

Fama, E., French, K. (1987). "Commodity futures prices, some evidence on forecast power, premiums, and the theory of storage." The Journal of Business 60(1): 55-73.

Fama, E., French, K. (1988). "Business cycles and the behavior of metals prices." The Journal of Finance 43(5): 1075-1093.

Frühwirth-Schnatter, S., Wagner, H. (2010). "Stochastic Model Specification Search for Gaussian and Partially Non-Gaussian State Space Models." Journal of Econometrics 154: 85-100.

Gao, A., Wang, G. (2005). "Asymmetric volatility of basis and the theory of storage." Journal of Futures Markets 25(4): 339-418.

Geman, H., Ohana, S. (2009). "Forward curves, scarcity and price volatility in oil and natural gas markets." Energy Economics 31: 576-585.

Geman, H., Smith, W. (2013). "Theory of storage, inventory and volatility in the LME base metals." Resources Policy 38 : $18-28$. 
Gkillas, K., Gupta, R., Pierdzioch, C.H. (2020). "Forecasting realized oil-price volatility: The role of financial stress and asymmetric loss." Journal of International Money and Finance 25: 102-137.

Gorton, G.B., Hayashi, F., Rouwenhorst, K.G. (2012). "The fundamentals of commodity futures returns." Review of Finance 17(1): 35-105.

Gorton, G.B., Rouwenhorst, K. (2006). "Facts and fantasies about commodity futures." Financial Analyst Journal 62: 47-68.

Griffin, J.E., Brown, P.J. (2010). "Inference with normal-gamma prior distributions in regression problems." Bayesian Analysis 5: 171-188.

Hakkio, C., Keeton, W. (2009). "Financial stress: What is it, how can it be measured, and why does it matter?" Federal Reserve Bank of Kansas City 17(1): $35-105$.

Hamilton, J.D., Wu, J.C. (2014). "Risk premia in crude oil futures prices." Journal of International Money and Finance 42: 9-37.

Jacquier, E., Polson, N.G., Rossi, P.E. (1994). "Bayesian analysis of stochastic volatility models." Journal of Business and Economic Statistics 12: $371-417$.

Junttila, J., Pesonen, J., Raatikainen, J. (2018). "Commodity market based hedging against stock market risk in times of financial crisis: The case of crude oil and gold." Journal of International Financial Markets, Institutions and Money 56: 255-280.

Kastner, G. (2016). "Dealing with stochastic volatility in time series using the R package stochvol." Journal of Statistical Software 69: 1-30.

Kastner G, Frühwirth-Schnatter S (2014). "Ancillarity-sufficiency interweaving strategy (ASIS) for boosting MCMC estimation of stochastic volatility models." Computational Statistics and Data Analysis 76: 408-423.

Kilian, L. (2009). "Not all oil price shocks are alike: Disentangling demand and supply shocks in the crude oil market." American Economic Review 99(3): 1053-1069.

Lee, J., Strazicich, M. (2003). "Minimum lagrange multiplier unit root test with two structural Breaks." The Review of Economics and Statistics 85(4): 10821089.

Mollick, A.V., Assefa, T.A. (2013). "U.S. stock returns and oil prices: The tale from daily data and the 2008-2009 financial crisis." Energy Economics 36: $1-18$.

Nakajima,J. (2011). "Time-varying parameter VAR model with stochastic volatility: An overview of methodology and empirical applications." Monetary and Economic Studies 29: 107-142.

Nazlioglu, S., Soytas, U., Gupta, R. (2015). "Oil prices and financial stress: A volatility spillover analysis." Energy Policy 82: $278-288$.

Ng, V.K., Pirrong, S.C. (1994). "Fundamentals and volatility: storage, spreads, and the dynamics of metals prices." The Journal of Business 67(2): 203-230.

Nikitopoulos, C.S., Squires, M., Thorp, S., Yeung, D. (2017)."Determinants of the crude oil futures curve: Inventory, consumption and volatility." Journal of Banking and Finance 84: 53-67.

Park, T., Case lia, G. (2008). "The Bayesian Lasso." Journal of the American Statistical Association 103: 681-686.

Pindyck, R.S. (1994). "Inventories and the Short-Run Dynamics of Commodity Prices." RAND Journal of Economics 25: 141-159.

Pindyck, R.S. (2001). "The dynamics of commodity and futures markets: a primer." The Energy Journal 22: 1-29.

Primiceri, G. (2005). "Time varying structural vector autoregressions and monetary policy." Review of Economic Studies 72: 821-852.

Qadan. M., Idilbi-Bayaa, Y. (2020). "Risk appetite and oil prices." Energy Economics 85, in press. 
Ready, R.C. (2018). "Oil Prices and the Stock Market". Review of Finance 22(1): 155-176.

Reboredo, J.C., Uddin, G.S. (2016). "Do financial stress and policy uncertainty have an impact on the energy and metals markets? A quantile regression approach." International Review of Economics and Finance 43: 284-298

Sari, R., Soytas, U., Hacihasanoglu, E. (2011). "Do global risk perceptions influence world oil prices." Energy Economics 33(3): 515-524.

Serletis, A., Hullernan, V. (1994). "Business Cycles and the behavior of energy prices." The Energy Journal 0(2): $125-134$.

Silvennoinen, A., Thorp, S. (2013). "Financialization, crisis and commodity correlation dynamics." Journal of International Financial Markets, Institutions and Money 24: 42-65.

Sims, C.A. (2001). "Evolving post-world war II U.S. inflation dynamics: Comment." NBER Macroeconomics Annual 16: $373-379$.

Singleton, K.J. (2014). "Investor flows and the 2008 boom/bust in oil prices." Management Science 60(2): 300-318.

Tang, K., Xiong, W. (2011). "Index investing and the financialization of commodities." Technical Report, Princeton University, NJ.

Symeonidis, L., Prokopczuk, M., Brooks, C., Lazar, E. (2012). "Futures basis, inventory and commodity price volatility: An empirical analysis." Economic Modelling 29: 2651-2663.

Wan, J-Y., Kao, C-W. (2015). "Interactions between oil and financial markets — Do conditions of financial stress matter?" Energy Economics 52: 160-175.

Table 1. Summary statistics

The descriptive statistics are reported for the original data and the unit root tests results are reported for the de-trended and de-seasonalized data. The $i a b_{2}, i a b_{4}$ and $i a b_{12}$ are the 2, 4 and 12-month interest-adjusted bases. The STLFSI is the Federal Reserve Bank of St. Louis' Financial Stress Index. The OECD petroleum and the US natural gas inventories are measured in million barrels and billion cubic feet, respectively. The ADF reports the $t$-statistics associated to the Augmented Dickey Fuller (1979) unit root test with constant, and Lee-Strazicich reports the $t$-statistics associated to the Lee and Strazicich (2003) minimum LM unit root test with constant and one or two structural breaks or crashes. *, ** and *** indicate statistical significance at the $10 \%, 5 \%$ and $1 \%$ levels, respectively.

\begin{tabular}{llllllll}
\hline Panel A (1994M01-2018M12) & Mean & Max & Min & SD & Skewness & ADF & Lee-Strazicich
\end{tabular}




\begin{tabular}{|c|c|c|c|c|c|c|c|}
\hline Crude oil $i a b_{2}$ & -0.000 & 0.106 & -0.070 & 0.019 & 0.207 & $-6.405^{* * *}$ & $-4.446 * * *$ \\
\hline Crude oil $i a b_{4}$ & -0.005 & 0.198 & -0.145 & 0.047 & 0.090 & $-3.656 * * *$ & $-3.982 * *$ \\
\hline Crude oil $i a b_{12}$ & -0.036 & 0.380 & -0.320 & 0.113 & 0.236 & $-3.624 * * *$ & $-3.633 * *$ \\
\hline Heating oil $i a b_{2}$ & -0.004 & 0.039 & -0.212 & 0.029 & -3.301 & $-6.789 * * *$ & $-6.101 * * *$ \\
\hline Heating oil $i a b_{4}$ & -0.004 & 0.120 & -0.312 & 0.057 & -1.982 & $-5.298 * * *$ & $-4.683 * * *$ \\
\hline Heating oil $i a b_{12}$ & -0.020 & 0.253 & -0.399 & 0.107 & -0.312 & $-5.364 * * *$ & $-4.501 * * *$ \\
\hline Natural gas $i a b_{2}$ & 0.017 & 0.337 & -0.252 & 0.053 & 0.960 & $-8.188 * * *$ & $-8.404 * * *$ \\
\hline Natural gas $i a b_{4}$ & 0.042 & 0.719 & -0.453 & 0.125 & 0.596 & $-7.795 * * *$ & $-5.482 * * *$ \\
\hline Natural gas $i a b_{12}$ & 0.057 & 0.897 & -0.492 & 0.198 & 0.512 & $-3.373 * *$ & $-5.253 * * *$ \\
\hline STLFSI & -0.000 & 4.707 & -1.541 & 1.003 & 0.869 & $-3.340 * *$ & $-3.403 * *$ \\
\hline OECD petroleum inventory & 4121.73 & 4707.30 & 3672.45 & 234.73 & 0.468 & $-4.421 * * *$ & $-3.070 *$ \\
\hline US NG inventory & 2401.73 & 3995.00 & 696.00 & 798.31 & -0.101 & $-4.068 * * *$ & $-5.067 * * *$ \\
\hline Panel B (1994M01-2006M12) & Mean & Max & Min & SD & Skewness & $\mathrm{ADF}$ & Lee Strazicich \\
\hline Crude oil $i a b_{2}$ & -0.008 & 0.039 & -0.071 & 0.020 & -0.488 & $-3.644 * * *$ & $-4.118 * * *$ \\
\hline Crude oil $i a b_{4}$ & -0.025 & 0.105 & -0.146 & 0.046 & -0.152 & $-3.248 * *$ & $-4.125 * * *$ \\
\hline Crude oil $i a b_{12}$ & -0.090 & 0.283 & -0.320 & 0.103 & 0.300 & $-3.953 * * *$ & $-4.478 * * *$ \\
\hline Heating oil $i a b_{2}$ & -0.008 & 0.037 & -0.212 & 0.036 & -2.606 & $-4.529 * * *$ & $-4.478 * * *$ \\
\hline Heating oil $i a b_{4}$ & 0.026 & 0.473 & -0.453 & 0.137 & 0.089 & $-3.732 * * *$ & $-5.350 * * *$ \\
\hline Heating oil $i a b_{12}$ & -0.062 & 0.253 & -0.399 & 0.118 & 0.007 & $-4.499 * * *$ & $-5.769 * * *$ \\
\hline Natural gas $i a b_{2}$ & 0.012 & 0.303 & -0.252 & 0.059 & 0.085 & $-5.903 * * *$ & $-4.162 * * *$ \\
\hline Natural gas $i a b_{4}$ & 0.026 & 0.473 & -0.453 & 0.137 & 0.089 & $-5.846 * * *$ & $-4.176 * * *$ \\
\hline Natural gas $i a b_{12}$ & -0.012 & 0.469 & -0.492 & 0.180 & 0.181 & $-3.360 * *$ & $-4.413 * *$ \\
\hline STLFSI & 0.423 & 1.436 & -0.686 & 0.542 & -0.633 & $-2.626^{*}$ & $-4.352 * *$ \\
\hline OECD petroleum inventory & 3947.20 & 4273.22 & 3672.45 & 127.21 & 0.308 & $-2.645^{*}$ & $-3.620 * *$ \\
\hline US NG inventory & 2120.78 & 3452.00 & 696.00 & 725.47 & -0.106 & $-3.077 * *$ & $-5.113 * * *$ \\
\hline Panel C (2009M01-2018M12) & Mean & Max & Min & SD & Skewness & $\mathrm{ADF}$ & Lee Strazicich \\
\hline Crude oil $i a b_{2}$ & -0.001 & 0.107 & -0.062 & 0.022 & 0.572 & $-4.294 * * *$ & -2.133 \\
\hline Crude oil $i a b_{4}$ & -0.008 & 0.199 & -0.139 & 0.052 & 0.329 & $-3.839 * * *$ & -2.265 \\
\hline Crude oil $i a b_{12}$ & -0.052 & 0.380 & -0.320 & 0.125 & 0.478 & $-3.798 * * *$ & -3.424 \\
\hline Heating oil $i a b_{2}$ & -0.002 & 0.039 & -0.212 & 0.033 & -3.230 & $-3.952 * * *$ & $-7.413 * * *$ \\
\hline Heating oil $i a b_{4}$ & -0.003 & 0.120 & -0.313 & 0.068 & -1.810 & $-3.821 * * *$ & $-4.200 * * *$ \\
\hline Heating oil $i a b_{12}$ & -0.029 & 0.253 & -0.399 & 0.129 & -0.163 & $-2.633^{*}$ & $-3.637 * *$ \\
\hline Natural gas $i a b_{2}$ & 0.024 & 0.337 & -0.252 & 0.059 & 1.685 & $-5.542 * * *$ & $-6.191 * * *$ \\
\hline Natural gas $i a b_{4}$ & 0.062 & 0.719 & -0.453 & 0.143 & 1.156 & $-4.455 * * *$ & $-4.926 * * *$ \\
\hline Natural gas $i a b_{12}$ & 0.070 & 0.897 & -0.492 & 0.219 & 0.674 & $-2.629 *$ & $-3.395 * *$ \\
\hline STLFSI & -0.758 & 3.015 & -1.541 & 0.838 & 2.710 & $-6.247 * * *$ & $-4.995^{*}$ \\
\hline OECD petroleum inventory & 4345.57 & 4707.30 & 4118.807 & 163.37 & 0.761 & $-3.093 * *$ & $-4.801 * * *$ \\
\hline US NG inventory & 2752.05 & 3995.00 & 824.00 & 764.97 & -0.306 & -2.015 & $-5.811 * *$ \\
\hline
\end{tabular}

Table 2. Regression results for before and after the 2008 global financial crisis

This table reports the results from estimating equation 4 in the text using the monthly de-trended and de-seasonalized data. $i a b_{2}$, $i a b_{4}$ and $i a b_{12}$ are the 2,4 and 12 month interest-adjusted bases, respectively. For crude oil and heating oil, the Inventory variable is the OECD petroleum inventory and for natural gas is the US natural gas inventory. The financial stress index is the Federal Reserve Bank of St. Louis' Financial Stress Index (STLFSI). The values are the coefficients, the values in brackets are the standardized coefficients and the values in parentheses are the HAC, standard errors (using a Bartlett kernel and Newey-West fixed bandwidth=50000). $* *$ and $* * *$ indicate statistical significance at the $5 \%$ and $1 \%$ levels, respectively.

\begin{tabular}{|c|}
\hline 1994M01-2006M12 \\
\hline$i a b_{4}$ \\
\hline
\end{tabular}




\begin{tabular}{|c|c|c|c|c|c|c|}
\hline \multirow[t]{2}{*}{ Intercept } & -0.001 & -0.003 & -0.015 & 0.001 & 0.004 & 0.016 \\
\hline & $(0.002)$ & $(0.004)$ & $(0.010)$ & $(0.002)$ & $(0.004)$ & $(0.012)$ \\
\hline \multirow[t]{3}{*}{ STLFSI } & -0.003 & -0.011 & -0.039 & $0.0130 * * *$ & $0.027 * * *$ & $0.063 * * *$ \\
\hline & {$[-0.074]$} & {$[-0.010]$} & {$[-0.149]$} & {$[0.540]$} & {$[0.490]$} & {$[0.468]$} \\
\hline & $(0.004)$ & $(0.001)$ & $(0.024)$ & $(0.003)$ & $(0.006)$ & $(0.010)$ \\
\hline \multirow[t]{3}{*}{ Inventory } & $0.000 * * *$ & $0.000 * * *$ & $0.000 * * *$ & $0.000 * * *$ & $0.000 * * *$ & $0.000 * * *$ \\
\hline & {$[0.646]$} & {$[0.697]$} & {$[0.725]$} & {$[0.275]$} & {$[0.343]$} & {$[0.353]$} \\
\hline & $(0.000)$ & $(0.000)$ & $(0.000)$ & $(0.000)$ & $(0.000)$ & $(0.000)$ \\
\hline$R^{2}$ & 0.451 & 0.537 & 0.611 & 0.462 & 0.465 & 0.450 \\
\hline \multirow[t]{2}{*}{$F$-statistic } & $62.913 * * *$ & $88.741 * * *$ & $120.461 * * *$ & $49.985 * * *$ & $50.604 * * *$ & $47.539 * * *$ \\
\hline & \multicolumn{6}{|c|}{ Heating oil } \\
\hline \multirow[t]{2}{*}{ Intercept } & -0.000 & -0.001 & -0.015 & -0.000 & 0.001 & 0.014 \\
\hline & $(0.003)$ & $(0.005)$ & $(0.011)$ & $(0.002)$ & $(0.003)$ & $(0.008)$ \\
\hline \multirow[t]{3}{*}{ STLFSI } & -0.005 & -0.003 & -0.020 & $0.005 * * *$ & $0.015^{* * *}$ & $0.053 * * *$ \\
\hline & {$[-0.072]$} & {$[-0.22]$} & {$[-0.065]$} & {$[0.191]$} & {$[0.310]$} & {$[0.488]$} \\
\hline & $(0.008)$ & $(0.014)$ & $(0.024)$ & $(0.001)$ & $(0.003)$ & $(0.009)$ \\
\hline \multirow[t]{3}{*}{ Inventory } & $0.000 * * *$ & $0.000 * * *$ & $0.001 * * *$ & $0.000 * * *$ & $0.000 * * *$ & $0.000 * * *$ \\
\hline & {$[0.538]$} & {$[0.734]$} & {$[0.793]$} & {$[0.360]$} & {$[0.409]$} & {$[0.431]$} \\
\hline & $(0.000)$ & $(0.000)$ & $(0.000)$ & $(0.000)$ & $(0.000)$ & $(0.000)$ \\
\hline$R^{2}$ & 0.317 & 0.522 & 0.662 & 0.210 & 0.346 & 0.559 \\
\hline \multirow[t]{2}{*}{$F$-statistic } & $35.538 * * *$ & $83.573 * * *$ & $146.393 * * *$ & $15.440 * * *$ & $30.716 * * *$ & $73.786 * * *$ \\
\hline & \multicolumn{6}{|c|}{ Natural gas } \\
\hline \multirow[t]{2}{*}{ Intercept } & 0.002 & 0.005 & -0.004 & -0.001 & -0.004 & 0.019 \\
\hline & $(0.003)$ & $(0.009)$ & $(0.014)$ & $(0.004)$ & $(0.010)$ & $(0.020)$ \\
\hline \multirow[t]{3}{*}{ STLFSI } & 0.005 & 0.000 & -0.003 & $0.010 * *$ & $0.031 * *$ & $0.138 * * *$ \\
\hline & {$[0.045]$} & {$[0.001]$} & {$[-0.007]$} & {$[0.184]$} & {$[0.222]$} & {$[0.451]$} \\
\hline & $(0.010)$ & $(0.020)$ & $(0.033)$ & $(0.005)$ & $(0.012)$ & $(0.022)$ \\
\hline \multirow[t]{3}{*}{ Inventory } & $0.000 * * *$ & $0.000 * * *$ & $0.000 * * *$ & $0.000 * * *$ & $0.000 * * *$ & $0.000 * * *$ \\
\hline & {$[0.488]$} & {$[0.595]$} & {$[0.744]$} & {$[0.472]$} & {$[0.554]$} & {$[0.604]$} \\
\hline & $(0.000)$ & $(0.000)$ & $(0.000)$ & $(0.000)$ & $(0.000)$ & $(0.000)$ \\
\hline$R^{2}$ & 0.233 & 0.353 & 0.555 & 0.281 & 0.390 & 0.645 \\
\hline$F$-statistic & $23.327 * * *$ & $41.917 * * *$ & $95.768 * * *$ & $22.902 * * *$ & $37.540 * * *$ & $106.443 * * *$ \\
\hline
\end{tabular}


Table 3. Nonlinear regression results for the full sample

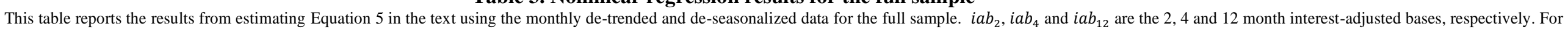

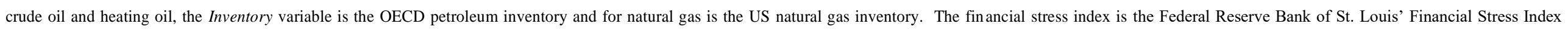

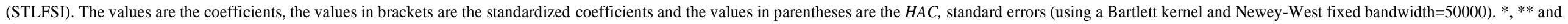
*** indicate statistical significance at the $10 \%, 5 \%$ and $1 \%$ levels, respectively.

\begin{tabular}{|c|c|c|c|c|c|c|c|c|c|}
\hline \multirow{3}{*}{$\begin{array}{l}\text { Explanatory variables } \\
\text { Intercept }\end{array}$} & \multicolumn{3}{|c|}{ Crude oil } & \multicolumn{3}{|c|}{ Heating oil } & \multicolumn{3}{|c|}{ Natural gas } \\
\hline & $i a b_{2}$ & $i a b_{4}$ & $i a b_{12}$ & $i a b_{2}$ & $i a b_{4}$ & $i a b_{12}$ & $i a b_{2}$ & $i a b_{4}$ & $i a b_{12}$ \\
\hline & 0.002 & 0.004 & 0.007 & $0.004^{*} *$ & $0.008 * *$ & 0.006 & 0.000 & 0.001 & -0.013 \\
\hline & $(0.001)$ & (0.004) & $(0.010)$ & -0.002 & $(0.004)$ & $(0.009)$ & $(0.003)$ & $(0.008)$ & $(0.013)$ \\
\hline \multirow[t]{3}{*}{ STLFSI } & -0.000 & -0.003 & -0.008 & -0.002 & -0.002 & -0.003 & $0.010^{*}$ & 0.020 & $0.056 * *$ \\
\hline & {$[-0.012]$} & {$[-0.055]$} & {$[-0.062]$} & {$[-0.080]$} & {$[-0.040]$} & {$[-0.025]$} & {$[0.171]$} & {$[0.160]$} & {$[0.225]$} \\
\hline & $(0.002)$ & $(0.006)$ & $(0.014)$ & $(0.004)$ & $(0.007)$ & $(0.014)$ & $(0.006)$ & $(0.012)$ & $(0.023)$ \\
\hline \multirow[t]{3}{*}{$S T L F S I^{2}$} & $0.002 *$ & $0.004 * *$ & $0.012 * * *$ & 0.001 & 0.002 & $0.007 *$ & -0.001 & -0.001 & 0.003 \\
\hline & {$[0.203]$} & {$[0.240]$} & {$[0.272]$} & [0.118] & [0.107] & {$[0.160]$} & {$[-0.096]$} & {$[-0.033]$} & {$[0.035]$} \\
\hline & $(0.000)$ & $(0.001)$ & $(0.004)$ & $(0.001)$ & $(0.002)$ & $(0.004)$ & $(0.001)$ & $(0.003)$ & $(0.007)$ \\
\hline \multirow[t]{3}{*}{ Inventory } & $0.000 * * *$ & $0.000 * * *$ & $0.000 * * *$ & $0.000 * * *$ & $0.000 * * *$ & $0.000 * * *$ & $0.000 * * *$ & $0.000 * * *$ & $0.000 * * *$ \\
\hline & {$[0.650]$} & {$[0.695]$} & {$[0.700]$} & {$[0.590]$} & {$[0.707]$} & {$[0.760]$} & {$[0.490]$} & {$[0.595]$} & {$[0.762]$} \\
\hline & $(0.000)$ & $(0.000)$ & $(0.000)$ & $(0.000)$ & $(0.000)$ & $(0.000)$ & $(0.000)$ & $(0.000)$ & $(0.000)$ \\
\hline \multirow[t]{3}{*}{ Inventory ${ }^{2}$} & $-0.000 * * *$ & $-0.000 * * *$ & $-0.000 * * *$ & $-0.000 * * *$ & $-0.000 * * *$ & $-0.000 * *$ & 0.000 & -0.000 & $0.000 * *$ \\
\hline & {$[-0.243]$} & {$[-0.229]$} & {$[-0.190]$} & {$[-0.283]$} & {$[-0.268]$} & {$[-0.171]$} & {$[0.024]$} & {$[-0.012]$} & {$[0.090]$} \\
\hline & $(0.000)$ & $(0.000)$ & $(0.000)$ & $(0.000)$ & $(0.000)$ & $(0.000)$ & $(0.000)$ & $(0.000)$ & $(0.000)$ \\
\hline \multirow[t]{3}{*}{ Interact } & $0.000 * * *$ & $0.000 * * *$ & $0.000 * * *$ & $0.000 *$ & $0.000 * *$ & $0.000 * * *$ & $0.000 *$ & $0.000 * * *$ & $0.000 * * *$ \\
\hline & {$[0.222]$} & {$[0.195]$} & {$[0.204]$} & {$[0.135]$} & {$[0.178]$} & {$[0.240]$} & {$[0.107]$} & {$[0.185]$} & {$[0.248]$} \\
\hline & $(0.000)$ & $(0.000)$ & $(0.000)$ & $(0.000)$ & $(0.000)$ & $(0.000)$ & $(0.000)$ & $(0.000)$ & $(0.000)$ \\
\hline \multicolumn{10}{|l|}{ Joint significance $F$ tests } \\
\hline STLFSI, STLFSI ${ }^{2}$ & $7.052 * * *$ & $11.635 * * *$ & $24.445 * * *$ & 1.392 & 2.063 & $8.394 * * *$ & $2.518^{*}$ & $8.325 * * *$ & $9.754 * * *$ \\
\hline Inventory, Inventory ${ }^{2}$ & $48.476 * * *$ & $58.844 * * *$ & $54.471 * * *$ & $20.894 * * *$ & $30.624 * * *$ & $40.368 * * *$ & $30.200 * * *$ & $46.102 * * *$ & $134.076 * * *$ \\
\hline STLFSI, STLFSI ${ }^{2}$, Interact & $9.700 * * *$ & $13.828 * * *$ & $26.548 * * *$ & $2.647 * *$ & $3.949 * * *$ & $11.896 * * *$ & 1.994 & $6.500 * * *$ & $10.193 * * *$ \\
\hline Inventory, Inventory ${ }^{2}$, Interact & $33.883 * * *$ & $43.847 * * *$ & $42.230 * * *$ & $14.052 * * *$ & $21.191 * * *$ & $29.935 * * *$ & $20.802 * * *$ & $30.744 * * *$ & $89.513 * * *$ \\
\hline$R^{2}$ & 0.452 & 0.497 & 0.522 & 0.318 & 0.453 & 0.546 & 0.241 & 0.372 & 0.606 \\
\hline$F$-statistic & $48.451 * * *$ & $57.966 * * *$ & $64.151 * * *$ & $27.351 * * *$ & $48.623 * * *$ & $69.714 * * *$ & $18.686 * * *$ & $34.911 * * *$ & $90.490 * * *$ \\
\hline
\end{tabular}


Figure 1a. Interested-adjusted basis
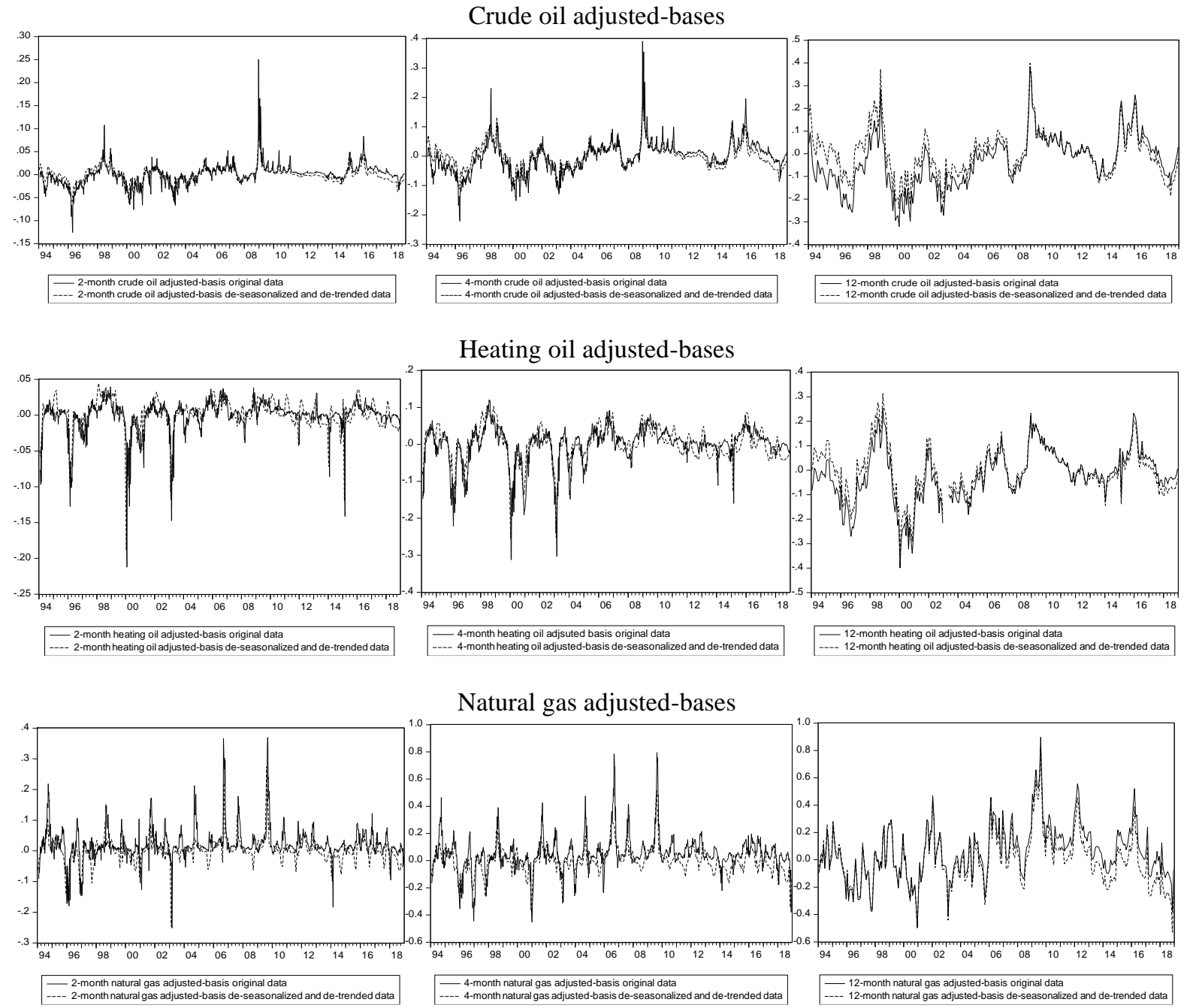

Figure 1b. Predictors

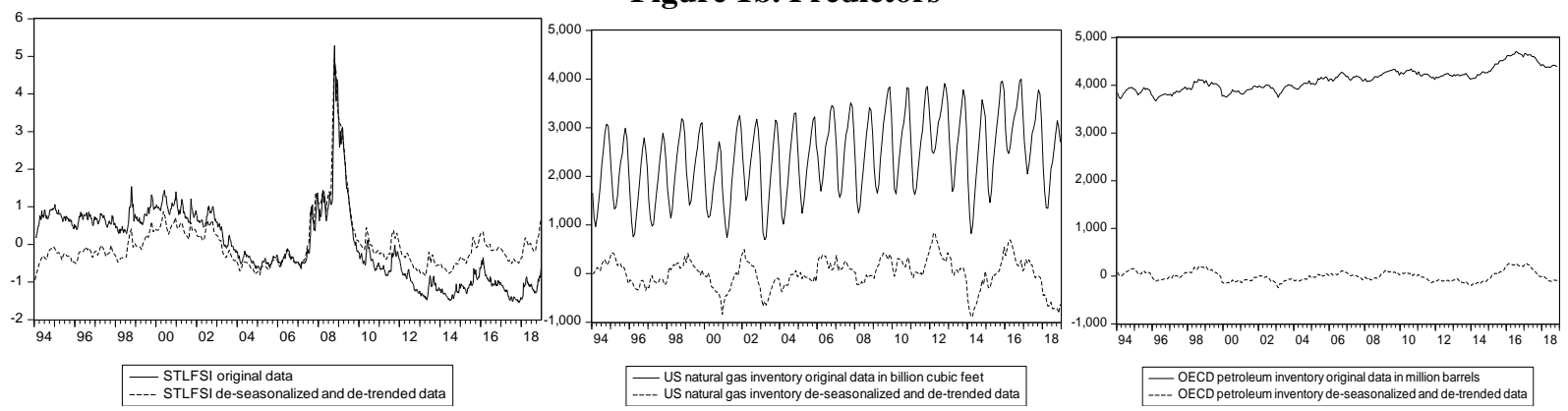


Figures 2a-2c. Time varying parameter estimations

These graphs report the results from estimating Equation 6 in the text using the monthly de-trended and de-seasonalized data. The dependent variable is the 12-month interest adjusted basis and the explanatory variables are the Federal Reserve Bank of St. Louis' Financial Stress Index (STLFSI) and inventory. The graphs visualize the evolution of the time varying parameters $\beta_{j}=\left(\beta_{j 0}, \ldots, \beta_{j T}\right), \mathrm{j}=1,2,3$ (including intercept that is not reported) over time. The median is displayed as a black line, and the grey shaded areas indicate the pointwise $90 \%$ to the $1 \%$ posterior credit intervals.

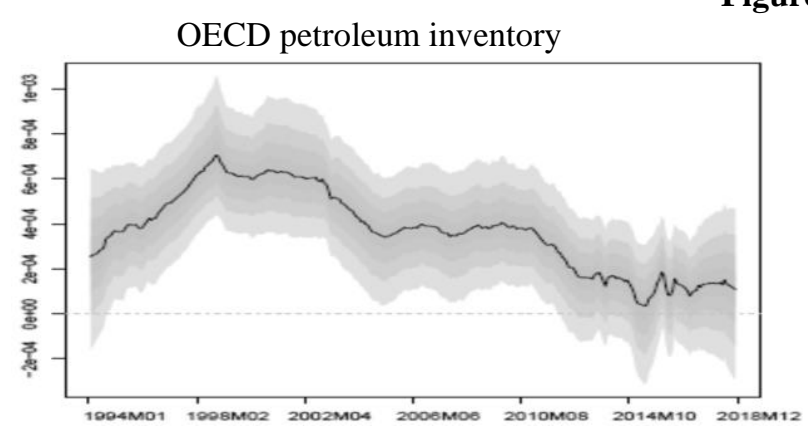

\section{Figures 2a. Crude oil}

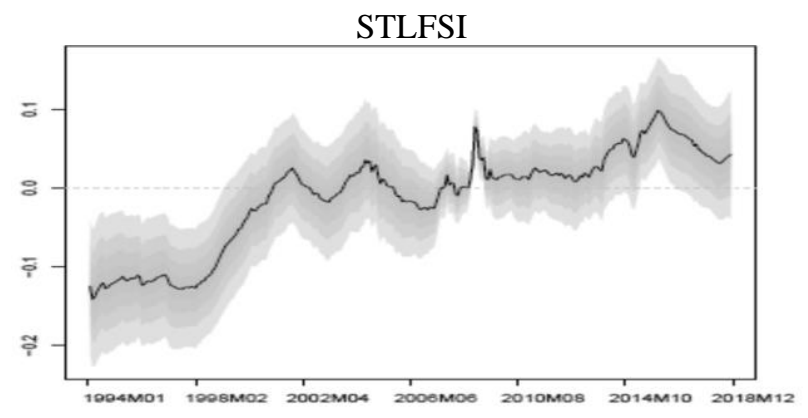

Figures 2b. Heating oil

OECD petroleum inventory

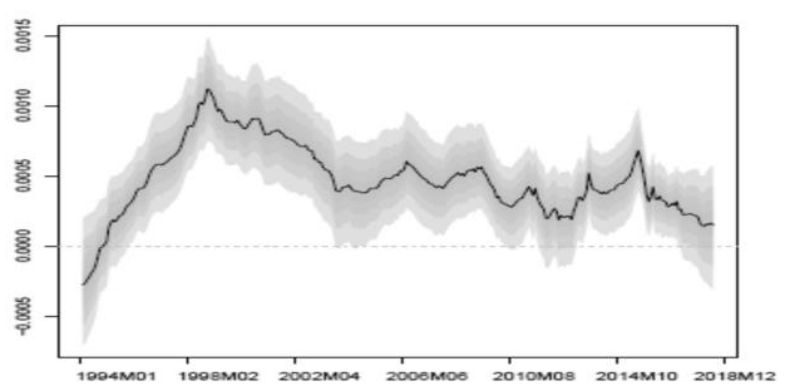

STLFSI

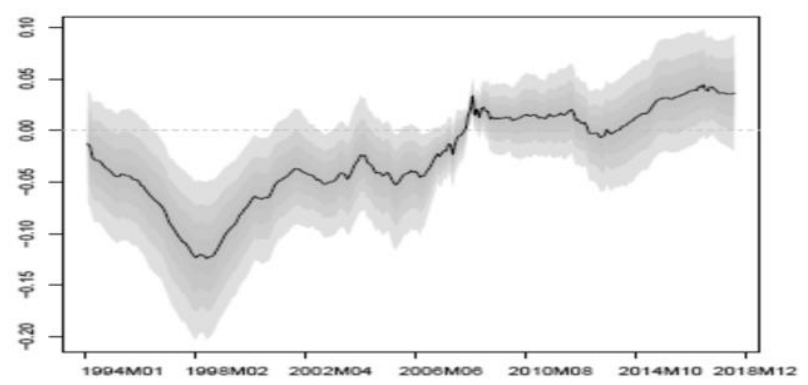

Figures 2c. Natural gas
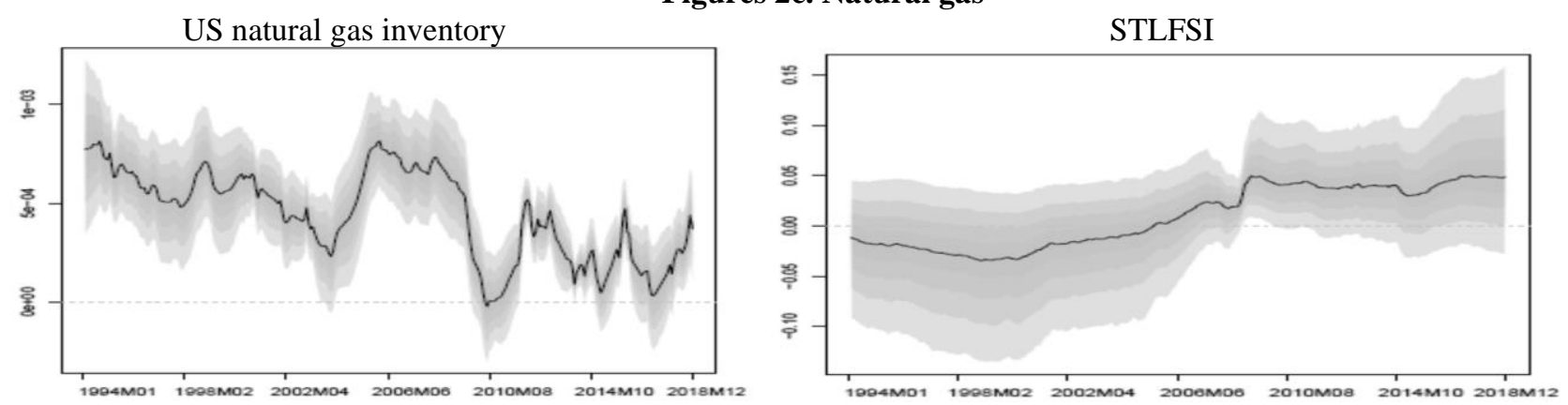


\title{
Online Appendix
}

\section{Financial Stress and Basis in Energy Markets}

\author{
Niaz Bashiri Behmiri ${ }^{a^{1}}$, Maryam Ahmadi ${ }^{b}$, Juha-Pekka Junttila ${ }^{c}$, Matteo Manera ${ }^{\mathrm{d}}$
}

${ }^{a}$ University of Stavanger, UiS Business School, Norway, ${ }^{b}$ University of Milan-Bicocca, Italy, ${ }^{c}$ University of Jyväskylä School of Business and Economics, Finland, ${ }^{\mathrm{d}}$ University of Milan-Bicocca and Fondazione Eni Enrico Mattei (FEEM), Italy

\section{Appendix 1. Alternative Financial Stress Indexes}

We apply two alternative financial stress indexes for robustness checks to estimate the following model:

$$
i a b_{t T}=\alpha_{0}+\alpha_{1} F S I_{t}+\alpha_{2} \text { Inventory }_{t}+u_{t}(1)
$$

where $i a b_{t T}$ corresponds to the 2, 4 and 12-month interest-adjusted bases, $F S I_{t}$ represents a financial stress index, and Inventor $y_{t}$ corresponds to the OECD petroleum inventory to explain the crude oil and heating oil and the US natural gas inventory to explain the natural gas interest-adjusted bases.

The first financial stress index alternative is the Federal Reserve Bank of Kansas City Financial Stress Index (KCFSI). This is a measure of the US financial market stress built on eleven financial market variables, such as various yield spreads and asset prices. Fundamentally, this index captures five key features of financial stress, namely, the increased uncertainty about the fundamental value of assets, behavior of other investors, the asymmetry of information, the decreased willingness to hold risky assets (flight to quality) and to hold illiquid assets (flight to liquidity) (see Hakkio and Keeton, 2009). A positive value of the KCFSI indicates that financial stress is above the long-run average and a negative value means that it is below the long-run average. We collect the KCFSI data from the Federal Reserve Bank of St. Louis Economic Database (FRED) as the end of period monthly observations, from January 1994 to December 2018. The results for the sub-samples of before and after the 2008 financial crisis are reported in Table 1a.

The second alternative financial stress index is the Chicago Board Options Exchange Volatility Index (VIX). This is a measure of market expectations of near-term volatility conveyed by the Standard and Poor's 500 index option prices and is

\footnotetext{
${ }^{1}$ Corresponding author, email address: bashiri.niaz@gmail.com.
} 
often known as a risk perception index. The VIX captures one key feature of financial stress, i.e., the uncertainty about fundamentals and behavior of other investors. Periods of high uncertainty may reduce investing in financial markets in general, and hence, we expect a negative effect on the commodity futures prices. We collect the VIX data from the Chicago Board of Options Exchange (CBOE) as the end of period monthly observations, from January 1994 to December 2018. The results for the sub-samples of before and after the 2008 financial crisis are reported in Table $1 \mathrm{~b}$.

[Table $1 \mathrm{a}$ and $1 \mathrm{~b}$ about here]

The results for the KCFSI is robust to the Federal Reserve Bank of St. Louis' Financial Stress Index (STLFSI) reported in the main text. This means that before the crisis, we do not find any significant effect and after the crisis there is a po sitive and significant effect from the KCFSI on the 2, 4 and 12 months adjusted-bases of crude oil, heating oil and natural gas. The results from the VIX also is robust to the STLFSI for crude oil and heating oil; however, it is different for natural gas, as we only find a significant effect from the VIX on the 12-month adjusted-basis of natural gas, and for the 2 and 4 month adjustedbases the coefficients associated to the VIX remain insignificant both before and after the 2008 crisis. These results show that, the three energy commodities are related to the financial stress indices that capture the overall financial condition of economy; however, crude oil and heating oil markets are more responsive to the uncertainty in stock markets compared to the natural gas one.

\section{Appendix 2. Alternative Inventory Measures}

For robustness check, we apply two alternative inventory measures to explain the crude oil and heating oil interestadjusted bases:

$$
i a b_{t T}=\alpha_{0}+\alpha_{1} \text { STLFSI }_{t}+\alpha_{2} \text { Inventory }_{t}+u_{t}
$$

where STLFSI $t$ is the Federal Reserve Bank of St. Louis' Financial Stress Index. For crude oil model, Inventory $y_{t}$ corresponds to the US petroleum as well as the US crude oil inventories, and for heating oil model, it corresponds to the US petroleum inventory. The results for the sub-samples of before and after the 2008 financial crisis are reported in Table 2.

[Table 2 about here]

Applying the US petroleum inventory to explain the crude oil and heating oil adjusted-bases, we find a robust result to the OECD petroleum inventory reported in the main text. This means that before and after the 2008 crisis, there is a positive 
and significant effect from the US petroleum inventory to the adjusted-basis of these two commodities; however, the magnitude of effects becomes smaller after the crisis. Applying the US crude oil inventory to explain the crude oil adjusted-basis, we find that, before and after the 2008 crisis, there is a positive and significant effect; however, the magnitude of effects become bigger after the crisis.

\section{Appendix 3. Alternative Time Splits}

We perform several robustness checks considering different time splits. Equation 2 is estimated for a) before the crisis from 1994M01-2007M06 and after the crisis from 2009M06-2018 M12, reported in Table 3a. b) Before the crisis from 1994M01-2007M12 and after the crisis from 2008M01-2018M12, without excluding the crisis period, reported in Table 3b. c) Before increasing financialization in commodity markets from 1994M01-2004M12, and after the surge in financialization from 2005M01-2018M12., reported in Table 3c.

[Table 3a-3c about here]

The results reported at Table 3a address no effect from financial stress on the three commodities adjusted-bases before the crisis from 1998M01-2007M06; however, for the time period of after the crisis from 2009M06-2018M12, there is evidence for a positive and significant impact on the 2, 4 and 12-month adjusted-bases of crude oil, 4 and 12-month adjusted-bases of heating oil and 12-month adjusted basis of natural gas. Table $3 \mathrm{~b}$ reporting the results for the time period of before the crisis from 1998M01-2007M12 and after the crisis from 2008M01-2018M12 reveals very robust results to the main text. Finally, the results obtained from estimations of before and after increasing commodity financialization in 2004 reported in Table $3 \mathrm{c}$ is also very robust to the results in the main text that the time split is before and after the 2008 global financial crisis with dropping the crisis period.

Therefore, if the crisis period is defined to begin and end 6 months later that what is defined in the main text, as reported in Table 3a, we still find that there is a positive effect after the crisis; however, for natural gas the effect is weak and only for longer maturity adjusted-basis. This shows that, for this commodity, some part of the positive effect obtained in the main text is due to including some part of the high crisis periods into the estimations of after the crisis. 


\section{Appendix 4. Alternative financial stress indexes in nonlinear regressions}

We perform robustness checks to validate the nonlinear model including the quadratics and the interaction terms. We regress the 2, 4 and 12-month interest-adjusted bases of crude oil, heating oil and natural gas on the alternative financial stress indexes, including the Federal Reserve Bank of Kansas City Financial Stress Index (KCFSI) and the VIX, as well as inventory, the squared terms of financial stress and inventory and the interaction term between financial stress and inventory. The aim is to capture the nonlinearity of relationship between the interest-adjusted bases, financial stress and inventory:

$$
i a b_{t T}=\alpha_{0}+\alpha_{1} F_{S I}+\alpha_{2} F S I^{2}+\alpha_{3} \text { Inventory }_{t}+\alpha_{4} \text { Inventory }^{2}+\alpha_{5} \text { Interact }+u_{t}
$$

[Table $4 \mathrm{a}-4 \mathrm{~b}$ about here]

The results for the full sample are reported in Tables $4 \mathrm{a}-4 \mathrm{~b}$. There is less evidence for the nonlinear increasing effects of the KCFSI and the VIX on the interest-adjusted bases, compared to the Federal Reserve Bank of St. Louis' Financial Stress Index (STLFSI) reported in the main text. However, the results from the interaction effect between inventory and the financial stress are in line with the initial estimation applying the STLFSI. This conclusion applies to the three commodities.

\section{Appendix 5. Time Varying Parameter Estimation with Alternative Financial Stress Indexes}

We apply Bitto and Fri.ihwirth-Schnatter (2019) approach to estimate the time varying parameter models with using the alternative financial stress indexes. The Federal Reserve Bank of Kansas City Financial Stress Index (KCFSI) results are reported in Figures 1a-1c, and the VIX results are reported in Figures 2a-2c. The dependent variable is the 12-month interestadjusted basis and the explanatory variables are financial stress and inventory.

[Figures 1a-1c about here]

[Figures 2a-2c about here]

Looking at the time varying coefficients of KCFSI, we find a very robust results compared to the STLFSI reported in the main text. For the three commodities, first, the parameters associated with inventory and KCFSI are time-varying; second, the parameter associated with inventory is decreasing over time; third, the parameter related to the KCFSI is increasing over time. Moreover, the sign of KCFSI coefficients shift from negative to positive after the 2008 global financial crisis and this applied to the three commodities. Focusing on the time varying coefficients of VIX, for crude oil and heating, we come to the 
same conclusion as the STLFSI and KCFSI. For natural gas, although the coefficients are time varying, but we do not find an increasing pattern over time. 
Tables 1a-1b. Regression results for the sub-samples with the alternative financial stress indexes

These tables report the results from estimating equation 1 in the online appendix using the monthly de-trended and de-seasonalized data. $i a b_{2}$, $i a b_{4}$ and $i a b_{12}$ are the 2, 4 and 12 month interest-adjusted bases, respectively. In Table 1a, the financial stress index is the Federal Reserve Bank of Kansas City Financial Stress Index (KCFSI) and in Table $1 \mathrm{~b}$ is the VIX. The values are the coefficients, the values in brackets are the standardized coefficients and the values in parentheses are the $H A C$, standard errors (using a Bartlett kernel and Newey-West fixed bandwidth=50000). ** and *** indicate statistical significance at the $5 \%$ and $1 \%$ levels, respectively.

Table 1a. Regression results for the sub-samples using KCFSI

\begin{tabular}{|c|c|c|c|c|c|c|}
\hline & \multicolumn{3}{|c|}{ 1994M01 2006M12 } & \multicolumn{3}{|c|}{ 2009M01 2018M12 } \\
\hline & $i a b_{2}$ & $i a b_{4}$ & $i a b_{12}$ & $i a b_{2}$ & $i a b_{4}$ & $i a b_{12}$ \\
\hline & \multicolumn{6}{|c|}{ Crude oil } \\
\hline \multirow[t]{2}{*}{ Intercept } & -0.000 & -0.001 & -0.010 & 0.000 & 0.002 & 0.010 \\
\hline & $(0.001)$ & $(0.004)$ & $(0.010)$ & $(0.001)$ & $(0.004)$ & $(0.011)$ \\
\hline \multirow[t]{3}{*}{ KCFSI } & 0.002 & 0.003 & -0.000 & $0.009 * * *$ & $0.021 * * *$ & $0.052 * * *$ \\
\hline & {$[0.080]$} & {$[0.061]$} & {$[-0.003]$} & {$[0.595]$} & {$[0.570]$} & {$[0.569]$} \\
\hline & $(0.002)$ & $(0.005)$ & $(0.013)$ & $(0.002)$ & $(0.004)$ & $(0.008)$ \\
\hline \multirow[t]{3}{*}{ OECD petroleum inventory } & $0.000 * * *$ & $0.000 * * *$ & $0.000 * * *$ & $0.000 * * *$ & $0.021 * * *$ & $0.000 * * *$ \\
\hline & {$[0.688]$} & {$[0.742]$} & {$[0.767]$} & {$[0.317]$} & {$[0.375]$} & {$[0.378]$} \\
\hline & $(0.000)$ & $(0.000)$ & $(0.000)$ & $(0.000)$ & $(0.000)$ & $(0.000)$ \\
\hline$R^{2}$ & 0.452 & 0.531 & 0.591 & 0.538 & 0.56 & 0.562 \\
\hline \multirow[t]{2}{*}{$F$-statistic } & $63.179 * * *$ & $86.771 * * *$ & $110.578^{* * *}$ & $67.684 * * *$ & $73.830 * *$ & $74.498 * * *$ \\
\hline & \multicolumn{6}{|c|}{ Heating oil } \\
\hline \multirow[t]{2}{*}{ Intercept } & 0.000 & 0.000 & -0.011 & -0.000 & 0.000 & 0.009 \\
\hline & $(0.003)$ & $(0.005)$ & $(0.010)$ & $(0.001)$ & $(0.003)$ & $(0.000)$ \\
\hline \multirow[t]{3}{*}{ KCFSI } & 0.000 & 0.003 & 0.006 & $0.004 * * *$ & $0.012 * * *$ & $0.041 * * *$ \\
\hline & {$[0.003]$} & {$[0.045]$} & {$[0.039]$} & {$[0.246]$} & {$[0.375]$} & {$[0.555]$} \\
\hline & $(0.003)$ & $(0.007)$ & $(0.012)$ & $(0.001)$ & $(0.002)$ & $(0.007)$ \\
\hline \multirow[t]{3}{*}{ OECD petroleum inventory } & $0.000 * * *$ & $0.000 * * *$ & $0.001 * * *$ & $0.000 * * *$ & $0.000 * * *$ & $0.000 * * *$ \\
\hline & {$[0.559]$} & {$[0.733]$} & {$[0.820]$} & {$[0.366]$} & {$[0.427]$} & {$[0.466]$} \\
\hline & $(0.000)$ & $(0.000)$ & $(0.000)$ & $(0.000)$ & $(0.000)$ & $(0.000)$ \\
\hline$R^{2}$ & 0.312 & 0.523 & 0.660 & 0.235 & 0.393 & 0.639 \\
\hline \multirow[t]{2}{*}{$F$-statistic } & $34.751 * * *$ & $84.059 * * *$ & $144.788 * * *$ & $17.845^{* * *}$ & $37.614 * * *$ & $102.909 * * *$ \\
\hline & \multicolumn{6}{|c|}{ Natural gas } \\
\hline \multirow[t]{2}{*}{ Intercept } & 0.002 & 0.007 & -0.000 & -0.001 & -0.006 & 0.011 \\
\hline & $(0.004)$ & $(0.009)$ & $(0.014)$ & $(0.004)$ & $(0.01)$ & $(0.016)$ \\
\hline \multirow[t]{3}{*}{ KCFSI } & 0.004 & 0.009 & 0.017 & $0.007 * *$ & $0.023 * *$ & $0.109 * * *$ \\
\hline & {$[0.073]$} & {$[0.066]$} & {$[0.069]$} & {$[0.190]$} & {$[0.250]$} & {$[0.528]$} \\
\hline & $(0.005)$ & $(0.012)$ & $(0.018)$ & $(0.003)$ & $(0.009)$ & $(0.016)$ \\
\hline \multirow[t]{3}{*}{ US NG inventory } & $0.000 * * *$ & $0.000 * * *$ & $0.000 * * *$ & $0.000 * * *$ & $0.000 * * *$ & $0.000 * * *$ \\
\hline & {$[0.493]$} & {$[0.606]$} & {$[0.757]$} & {$[0.441]$} & {$[0.511]$} & {$[0.512]$} \\
\hline & $(0.000)$ & $(0.000)$ & $(0.000)$ & $(0.000)$ & $(0.000)$ & $(0.000)$ \\
\hline$R^{2}$ & 0.236 & 0.358 & 0.560 & 0.281 & 0.340 & 0.700 \\
\hline$F$-statistic & $23.740 * * *$ & $42.699 * * *$ & $97.594 * * *$ & $22.906 * * *$ & $38.956 * * *$ & $136.839 * * *$ \\
\hline
\end{tabular}


Table 1b. Regression results for the sub-samples using VIX

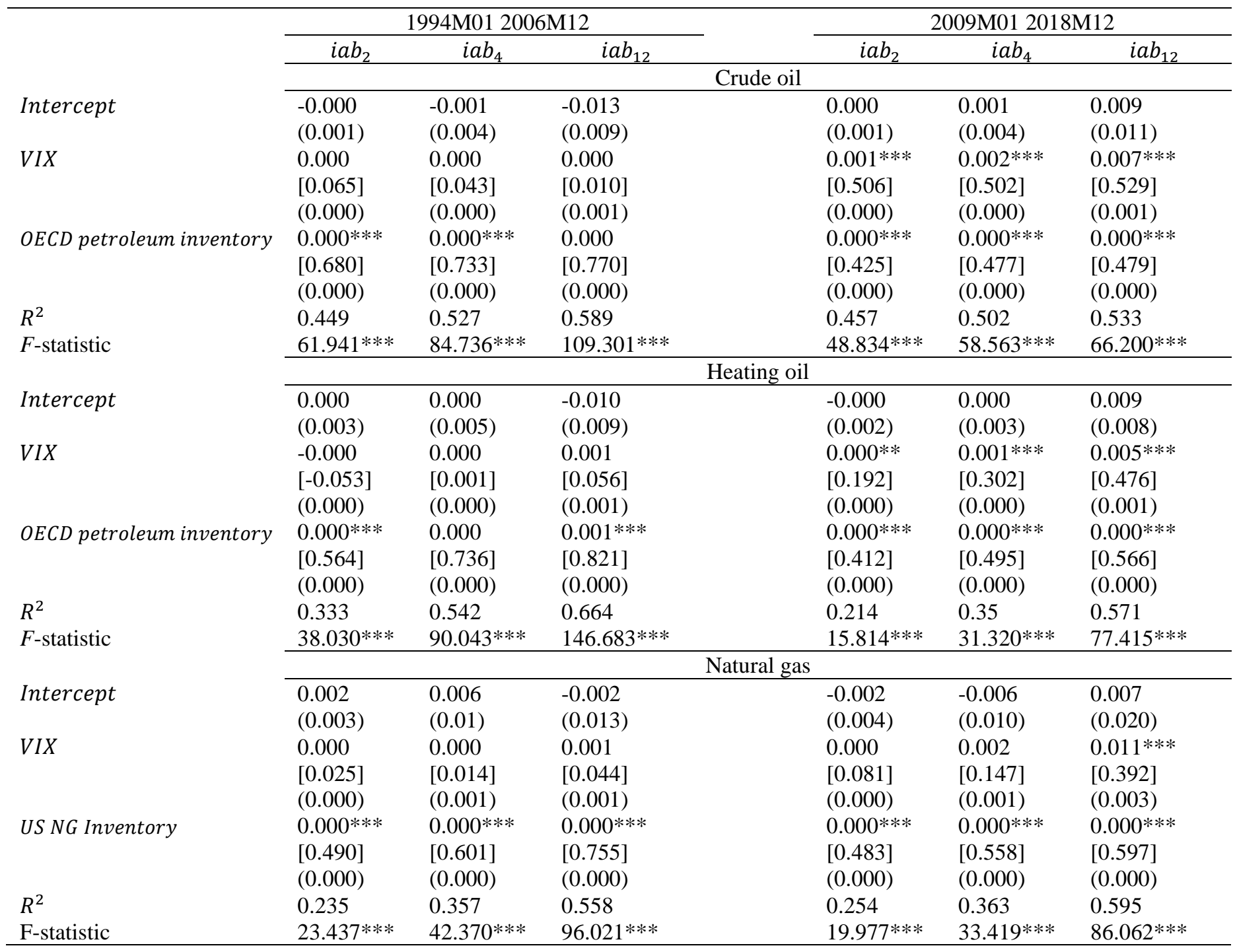


Table 2. Regression results for the sub-samples with alternative inventory measures

This table reports the results from estimating equation 1 in the online appendix using the monthly de-trended and de-seasonalized data. $i a b_{2}, i a b_{4}$ and $i a b_{12}$ are the 2, 4 and 12 month interest-adjusted bases, respectively. The financial stress index is the Federal Reserve Bank of St. Louis' Financial Stress Index (STLFSI). The values are the coefficients, the values in brackets are the standardized coefficients and the values in parentheses are the $H A C$, standard errors (using a Bartlett kernel and Newey-West fixed bandwidth=50000). ** and $* * *$ indicate statistical significance at the $5 \%$ and $1 \%$ levels, respectively.

\begin{tabular}{|c|c|c|c|c|c|c|}
\hline & \multicolumn{3}{|c|}{ 1994M01 2006M12 } & \multicolumn{3}{|c|}{ 2009M01 2018M12 } \\
\hline & $i a b_{2}$ & $i a b_{4}$ & $i a b_{12}$ & $i a b_{2}$ & $i a b_{4}$ & $i a b_{12}$ \\
\hline & \multicolumn{6}{|c|}{ Crude oil } \\
\hline \multirow[t]{2}{*}{ Intercept } & -0.000 & -0.003 & -0.013 & 0.000 & 0.002 & 0.011 \\
\hline & $(0.002)$ & $(0.006)$ & $(0.015)$ & $(0.002)$ & $(0.005)$ & $(0.013)$ \\
\hline \multirow[t]{3}{*}{ STLFSI } & -0.005 & -0.014 & -0.041 & $0.013 * * *$ & $0.030 * * *$ & $0.070 * * *$ \\
\hline & {$[-0.114]$} & {$[-0.128]$} & {$[-0.156]$} & {$[0.580]$} & {$[0.540]$} & {$[0.518]$} \\
\hline & $(0.004)$ & $(0.011)$ & $(0.028)$ & $(0.003)$ & $(0.006)$ & $(0.010)$ \\
\hline \multirow[t]{3}{*}{ US petroleum inventory } & $0.000 * * *$ & $0.000 * * *$ & $0.000 * * *$ & $0.000 * *$ & $0.000 * * *$ & $0.000 * * *$ \\
\hline & {$[0.396]$} & {$[0.467]$} & {$[0.550]$} & {$[0.227]$} & {$[0.302]$} & {$[0.334]$} \\
\hline & $(0.000)$ & $(0.000)$ & $(0.000)$ & $(0.000)$ & $(0.000)$ & $(0.000)$ \\
\hline$R^{2}$ & 0.203 & 0.279 & 0.39 & 0.434 & 0.44 & 0.44 \\
\hline \multirow[t]{2}{*}{$F$-statistic } & $19.528 * * *$ & $29.683 * * *$ & $48.982 * * *$ & $44.916 * * *$ & $46.027 * * *$ & $45.975 * * *$ \\
\hline & \multicolumn{6}{|c|}{ Crude oil } \\
\hline \multirow[t]{2}{*}{ Intercept } & -0.000 & -0.002 & -0.01 & 0.000 & 0.001 & 0.01 \\
\hline & $(0.002)$ & $(0.007)$ & $(0.016)$ & $(0.001)$ & $(0.004)$ & $(0.011)$ \\
\hline \multirow[t]{3}{*}{ STLFSI } & -0.005 & -0.011 & -0.023 & $0.012 * * *$ & $0.027 * * *$ & $0.063 * * *$ \\
\hline & {$[-0.113]$} & {$[-0.101]$} & {$[-0.089]$} & {$[0.527]$} & {$[0.485]$} & {$[0.465]$} \\
\hline & $(0.006)$ & $(0.014)$ & $(0.035)$ & $(0.003)$ & $(0.006)$ & $(0.011)$ \\
\hline \multirow[t]{3}{*}{ US crude oil inventory } & $0.000 *$ & $0.000 * *$ & $0.000 * * *$ & $0.000 * * *$ & $0.000 * * *$ & $0.000 * * *$ \\
\hline & {$[0.234]$} & {$[0.317]$} & {$[0.428]$} & {$[0.373]$} & {$[0.431]$} & {$[0.447]$} \\
\hline & $(0.000)$ & $(0.000)$ & $(0.009)$ & $(0.000)$ & $(0.000)$ & $(0.000)$ \\
\hline$R^{2}$ & 0.1 & 0.151 & 0.24 & 0.514 & 0.526 & 0.52 \\
\hline \multirow[t]{2}{*}{$F$-statistic } & $8.588 * * *$ & $13.666 * * *$ & $24.165 * * *$ & $62.075 * * *$ & $64.984 * * *$ & $63.170 * * *$ \\
\hline & \multicolumn{6}{|c|}{ Heating oil } \\
\hline \multirow[t]{2}{*}{ Intercept } & -0.000 & -0.000 & -0.011 & -0.000 & 0.000 & 0.01 \\
\hline & $(0.003)$ & $(0.007)$ & $(0.017)$ & $(0.002)$ & $(0.004)$ & $(0.009)$ \\
\hline \multirow[t]{3}{*}{ STLFSI } & -0.008 & -0.006 & -0.024 & $0.007 * * *$ & $0.019 * * *$ & $0.060 * * *$ \\
\hline & {$[-0.103]$} & {$[-0.042]$} & {$[-0.081]$} & {$[0.262]$} & {$[0.392]$} & {$[0.550]$} \\
\hline & $(0.008)$ & $(0.016)$ & $(0.033)$ & $(0.001)$ & $(0.003)$ & $(0.007)$ \\
\hline \multirow[t]{3}{*}{ US petroleum invenory } & $0.000 * * *$ & $0.000 * * *$ & $0.000 * * *$ & $0.000 * *$ & $0.000 * *$ & $0.000 * * *$ \\
\hline & {$[0.337]$} & {$[0.505]$} & {$[0.563]$} & {$[0.220]$} & {$[0.256]$} & [0.390] \\
\hline & $(0.000)$ & $(0.000)$ & $(0.000)$ & $(0.000)$ & $(0.000)$ & $(0.000)$ \\
\hline$R^{2}$ & 0.15 & 0.273 & 0.357 & 0.137 & 0.254 & 0.53 \\
\hline$F$-statistic & $13.547 * * *$ & $28.741 * * * *$ & $41.482 * * *$ & $9.298 * * *$ & $19.982 * * *$ & $65.886 * * *$ \\
\hline
\end{tabular}


Tables 3a-3c. Regression results for the sub-samples

These tables report the results from estimating equation 2 in the online appendix using the monthly de-trended and de-seasonalized data. $i a b_{2}, i a b_{4}$ and $i a b_{12}$ are the 2, 4 and 12 month interest-adjusted bases, respectively. The financial stress index is the Federal Reserve Bank of St. Louis' Financial Stress Index (STLFSI). The values are the coefficients, the values in brackets are the standardized coefficients and the values in parentheses are the HAC, standard errors (using a Bartlett kernel and Newey-West fixed bandwidth=50000). *, ** and *** indicate statistical significance at the 10\%, 5\% and 1\% levels, respectively.

Table 3a. Regression results for before and after the 2008 global financial crisis

\begin{tabular}{|c|c|c|c|c|c|c|}
\hline & \multicolumn{3}{|c|}{ 1994M01 2007M06 } & \multicolumn{3}{|c|}{ 2009M06 2018M12 } \\
\hline & $i a b_{2}$ & $i a b_{4}$ & $i a b_{12}$ & $i a b_{2}$ & $i a b_{4}$ & $i a b_{12}$ \\
\hline & \multicolumn{6}{|c|}{ Crude oil } \\
\hline \multirow[t]{2}{*}{ Intercept } & -0.000 & -0.003 & -0.014 & 0.000 & 0.002 & 0.014 \\
\hline & $(0.002)$ & $(0.004)$ & $(0.010)$ & $(0.001)$ & $(0.005)$ & $(0.014)$ \\
\hline \multirow[t]{3}{*}{ STLFSI } & -0.004 & -0.012 & $-0.041 *$ & $0.006^{*}$ & $0.018^{*}$ & $0.056 * *$ \\
\hline & {$[-0.090]$} & {$[-0.113]$} & {$[-0.160]$} & {$[0.196]$} & {$[0.206]$} & {$[0.250]$} \\
\hline & $(0.004)$ & $(0.01)$ & $(0.024)$ & $(0.003)$ & $(0.010)$ & $0.000 * * *$ \\
\hline \multirow[t]{3}{*}{ OECD petroleum inventory } & $0.000 * * *$ & $0.000 * * *$ & $0.000 * * *$ & $0.000 * * *$ & $0.000 * * *$ & $(0.026)$ \\
\hline & {$[0.640]$} & {$[0.691]$} & {$[0.721]$} & {$[0.440]$} & {$[0.455]$} & {$[0.413]$} \\
\hline & $(0.000)$ & $(0.000)$ & $(0.000)$ & $(0.000)$ & $(0.000)$ & $(0.000)$ \\
\hline$R^{2}$ & 0.450 & 0.537 & 0.613 & 0.297 & 0.322 & 0.311 \\
\hline \multirow[t]{2}{*}{$F$-statistic } & $65.265 * * *$ & $92.340 * * *$ & $126.161 * * *$ & $23.517 * * *$ & $26.360 * * *$ & $25.100 * * *$ \\
\hline & \multicolumn{6}{|c|}{ Heating oil } \\
\hline \multirow[t]{2}{*}{ Intercept } & -0.000 & -0.000 & -0.014 & -0.000 & 0.002 & $0.019 *$ \\
\hline & $(0.003)$ & $(0.005)$ & $(0.010)$ & $(0.001)$ & $(0.004)$ & $(0.011)$ \\
\hline \multirow[t]{3}{*}{ STLFSI } & -0.006 & -0.004 & -0.021 & 0.006 & $0.020 * *$ & $0.073 * * *$ \\
\hline & {$[-0.078]$} & {$[-0.027]$} & {$[-0.073]$} & {$[0.128]$} & {$[0.221]$} & {$[0.390]$} \\
\hline & $(0.008)$ & $(0.014)$ & $(0.024)$ & $(0.004)$ & $(0.010)$ & $(0.022)$ \\
\hline \multirow[t]{3}{*}{ OECD petroleum inventory } & $0.000 * * *$ & $0.000 * * *$ & $0.001 * * *$ & $0.000 * * *$ & $0.000 * * *$ & $0.000 * * *$ \\
\hline & {$[0.536]$} & {$[0.714]$} & {$[0.790]$} & {$[0.353]$} & {$[0.408]$} & {$[0.440]$} \\
\hline & $(0.000)$ & $(0.000)$ & $(0.000)$ & $(0.000)$ & $(0.000)$ & $(0.000)$ \\
\hline$R^{2}$ & 0.32 & 0.523 & 0.662 & 0.176 & 0.284 & 0.477 \\
\hline \multirow[t]{2}{*}{$F$-statistic } & $37.287 * * *$ & $87.170 * * *$ & $152.212 * * *$ & $11.870 * * *$ & $22.099 * * *$ & $50.676 * * *$ \\
\hline & \multicolumn{6}{|c|}{ Natural gas } \\
\hline \multirow[t]{2}{*}{ Intercept } & 0.002 & 0.004 & -0.005 & 0.002 & 0.002 & 0.017 \\
\hline & $(0.003)$ & $(0.010)$ & $(0.014)$ & $(0.006)$ & $(0.017)$ & $(0.028)$ \\
\hline \multirow[t]{3}{*}{ STLFSI } & 0.005 & 0.003 & -0.001 & 0.023 & 0.058 & $0.133^{*}$ \\
\hline & {$[0.050]$} & {$[0.011]$} & {$[-0.004]$} & {$[0.214]$} & {$[0.225]$} & {$[0.256]$} \\
\hline & $(0.010)$ & $(0.020)$ & $(0.032)$ & $(0.017)$ & $(0.043)$ & $(0.071)$ \\
\hline \multirow[t]{3}{*}{ US NG inventory } & $0.000 * * *$ & $0.000 * * *$ & $0.000 * * *$ & $0.000 * * *$ & $0.000 * * *$ & $0.000 * * *$ \\
\hline & {$[0.486]$} & {$[0.594]$} & {$[0.742]$} & {$[0.454]$} & {$[0.538]$} & {$[0.661]$} \\
\hline & $(0.000)$ & $(0.000)$ & $(0.000)$ & $(0.000)$ & $(0.000)$ & $(0.000)$ \\
\hline$R^{2}$ & 0.231 & 0.350 & 0.551 & 0.295 & 0.394 & 0.578 \\
\hline$F$-statistic & $23.902 * * *$ & $42.970 * * *$ & $97.844 * * *$ & $23.461 * * *$ & $36.520 * * *$ & $76.892 * * *$ \\
\hline
\end{tabular}


Table 3b. Regression results for before and after the 2008 global financial crisis

\begin{tabular}{|c|c|c|c|c|c|c|}
\hline & \multicolumn{3}{|c|}{ 1994M01 2007M12 } & \multicolumn{3}{|c|}{ 2008M01 2018M12 } \\
\hline & $i a b_{2}$ & $i a b_{4}$ & $i a b_{12}$ & $i a b_{2}$ & $i a b_{4}$ & $i a b_{12}$ \\
\hline & \multicolumn{6}{|c|}{ Crude oil } \\
\hline \multirow{2}{*}{ Intercept } & -0.000 & -0.003 & -0.014 & -0.000 & 0.001 & 0.009 \\
\hline & $(0.001)$ & $(0.004)$ & $(0.009)$ & $(0.001)$ & $(0.004)$ & $(0.012)$ \\
\hline \multirow[t]{3}{*}{ STLFSI } & -0.004 & $-0.013 *$ & $-0.038 * *$ & $0.007 * * *$ & $0.017 * * *$ & $0.045^{* * *}$ \\
\hline & {$[-0.104]$} & {$[-0.128]$} & {$[-0.162]$} & {$[0.457]$} & {$[0.447]$} & {$[0.463]$} \\
\hline & $(0.003)$ & $(0.007)$ & $(0.019)$ & $(0.002)$ & $(0.005)$ & $(0.011)$ \\
\hline \multirow[t]{3}{*}{ OECD petroleum inventory } & $0.000 * * *$ & $0.000 * * *$ & $0.000 * * *$ & $0.000 * * *$ & $0.000 * * *$ & $0.000 * * *$ \\
\hline & {$[0.633]$} & [0.684] & {$[0.718]$} & {$[0.353]$} & {$[0.403]$} & {$[0.340]$} \\
\hline & $(0.000)$ & $(0.000)$ & $(0.000)$ & $(0.000)$ & $(0.000)$ & $(0.000)$ \\
\hline$R^{2}$ & 0.450 & 0.536 & 0.610 & 0.386 & 0.422 & 0.434 \\
\hline \multirow{2}{*}{$F$-statistic } & $67.696 * * *$ & $95.393 * * *$ & $129.578 * * *$ & $40.354 * * *$ & $46.806 * * *$ & $49.217 * * *$ \\
\hline & \multicolumn{6}{|c|}{ Heating oil } \\
\hline \multirow[t]{2}{*}{ Intercept } & -0.000 & -0.000 & -0.014 & -0.000 & 0.000 & 0.008 \\
\hline & $(0.002)$ & $(0.005)$ & $(0.009)$ & $(0.001)$ & $(0.004)$ & $(0.009)$ \\
\hline \multirow[t]{3}{*}{ STLFSI } & -0.005 & -0.002 & -0.020 & $0.005 * * *$ & $0.012 * * *$ & $0.035 * * *$ \\
\hline & {$[-0.074]$} & {$[-0.017]$} & {$[-0.075]$} & {$[0.261]$} & {$[0.358]$} & {$[0.470]$} \\
\hline & $(0.006)$ & $(0.011)$ & $(0.019)$ & $(0.001)$ & $(0.002)$ & $(0.007)$ \\
\hline \multirow[t]{3}{*}{ OECD petroleum inventory } & $0.000 * * *$ & $0.000 * * *$ & $0.001 * * *$ & 0.0000584 & $0.000 * * *$ & $0.000 * * *$ \\
\hline & {$[0.538]$} & {$[0.717]$} & [0.789] & {$[0.362]$} & {$[0.432]$} & {$[0.486]$} \\
\hline & $(0.000)$ & $(0.000)$ & $(0.000)$ & $(0.000)$ & $(0.000)$ & $(0.000)$ \\
\hline$R^{2}$ & 0.319 & 0.522 & 0.663038 & 0.230 & 0.365 & 0.531 \\
\hline \multirow{2}{*}{$F$-statistic } & $38.727 * * *$ & $90.097 * * *$ & $158.399 * * *$ & $19.174 * * *$ & $36.925 * * *$ & $72.648 * * *$ \\
\hline & \multicolumn{6}{|c|}{ Natural gas } \\
\hline \multirow[t]{2}{*}{ Intercept } & 0.003 & 0.007 & -0.002 & -0.002 & -0.007 & -0.000 \\
\hline & $(0.003)$ & $(0.009)$ & $(0.012)$ & $(0.003)$ & $(0.009)$ & $(0.020)$ \\
\hline \multirow[t]{3}{*}{ STLFSI } & 0.009 & 0.013 & 0.010 & $(0.004)$ & $0.018 * * *$ & $0.067 * *$ \\
\hline & [0.089] & {$[0.056]$} & {$[0.026]$} & {$[0.118]$} & {$[0.195]$} & {$[0.327]$} \\
\hline & $(0.008)$ & $(0.017)$ & $(0.026)$ & $(0.002)$ & $(0.006)$ & $(0.027)$ \\
\hline \multirow[t]{3}{*}{ US NG inventory } & $0.000 * * *$ & $0.000 * * *$ & $0.000 * * *$ & $0.000 * * *$ & $0.000 * * *$ & $0.000 * * *$ \\
\hline & [0.491] & {$[0.602]$} & {$[0.748]$} & {$[0.490]$} & {$[0.575]$} & {$[0.659]$} \\
\hline & $(0.000)$ & $(0.000)$ & $(0.000)$ & $(0.000)$ & $(0.000)$ & $(0.000)$ \\
\hline$R^{2}$ & 0.239 & 0.358 & 0.556 & 0.258 & 0.375 & 0.553 \\
\hline$F$-statistic & $25.944 * * *$ & $46.061 * * *$ & $103.347 * * *$ & $22.429 * * *$ & $38.804 * * *$ & $79.998 * * *$ \\
\hline
\end{tabular}


Table 3c. Regression results for before and after the 2005 increasing financialization

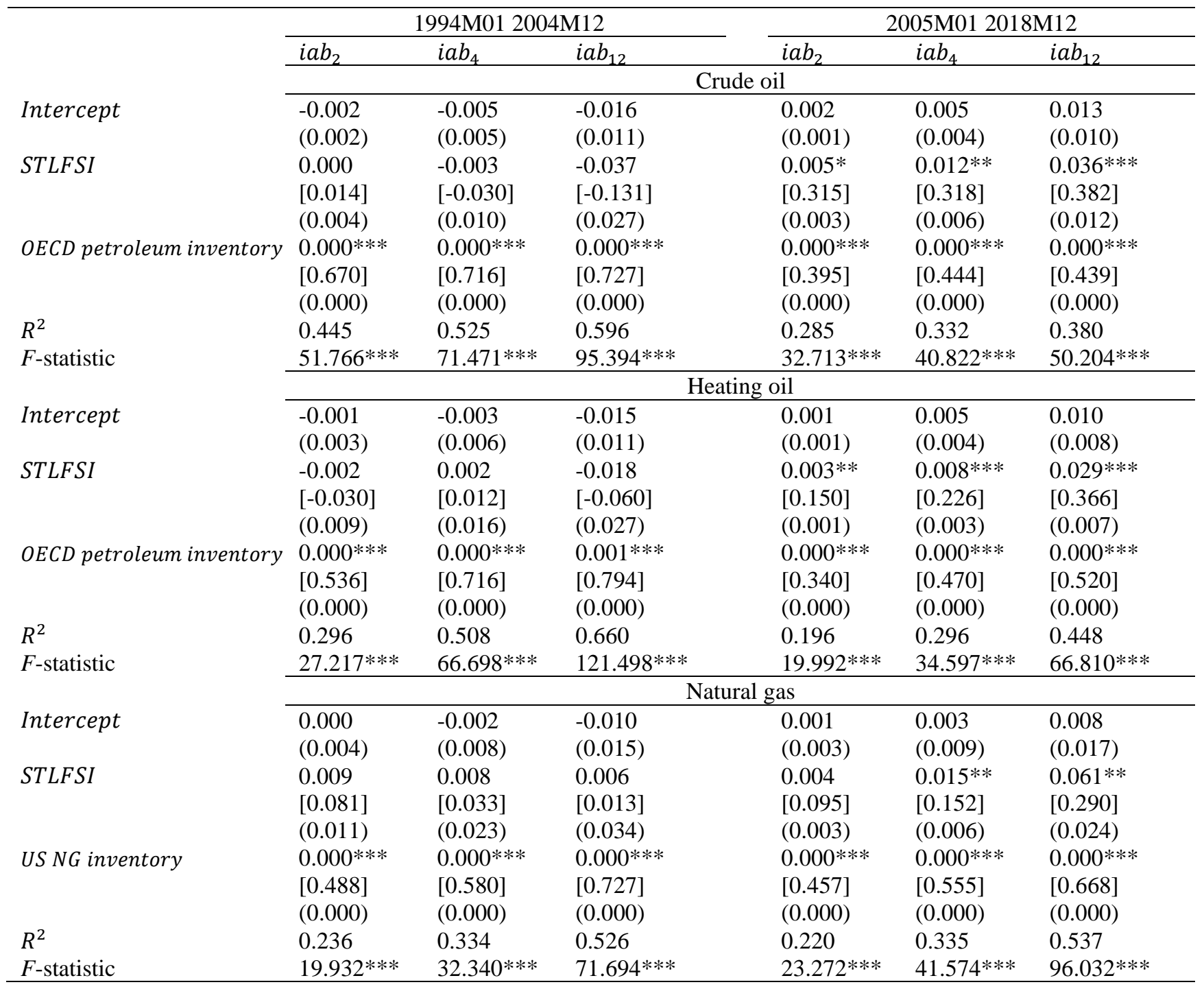




\section{Tables 4a-4b. Nonlinear regression results for the full sample with the alternative financial stress indices}

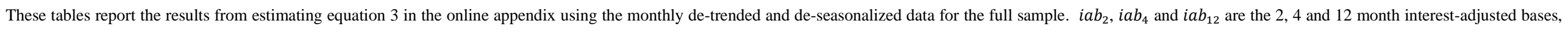

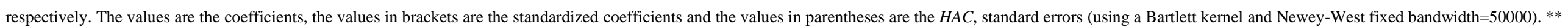
and $* * *$ indicate statistical significance at the $5 \%$ and $1 \%$ levels, respectively.

Table 4a. Nonlinear regression results for the full sample using KCFSI

\begin{tabular}{|c|c|c|c|c|c|c|c|c|c|}
\hline \multirow[b]{2}{*}{ Explanatory variables } & \multicolumn{3}{|c|}{ Crude oil } & \multicolumn{3}{|c|}{ Heating oil } & \multicolumn{3}{|c|}{ Natural gas } \\
\hline & $i a b_{2}$ & $i a b_{4}$ & $i a b_{12}$ & $i a b_{2}$ & $i a b_{4}$ & $i a b_{12}$ & $i a b_{2}$ & $i a b_{4}$ & $i a b_{12}$ \\
\hline \multirow[t]{2}{*}{ Intercept } & 0.002 & 0.006 & 0.010 & $0.005 * * *$ & $0.010 * *$ & 0.010 & -0.000 & 0.001 & -0.016 \\
\hline & $(0.001)$ & $(0.004)$ & $(0.011)$ & $(0.002)$ & $(0.004)$ & $(0.009)$ & $(0.003)$ & $(0.008)$ & $(0.013)$ \\
\hline \multirow[t]{3}{*}{$K C F S I$} & 0.002 & 0.006 & 0.013 & 0.001 & 0.005 & 0.014 & 0.005 & 0.013 & $0.037 * *$ \\
\hline & {$[0.162]$} & {$[0.161]$} & {$[0.140]$} & {$[0.071]$} & {$[0.109]$} & {$[0.150]$} & {$[0.127]$} & {$[0.144]$} & {$[0.210]$} \\
\hline & $(0.001)$ & $(0.004)$ & $(0.010)$ & $(0.002)$ & $(0.005)$ & $(0.010)$ & $(0.005)$ & $(0.010)$ & $(0.016)$ \\
\hline \multirow[t]{3}{*}{$K C F S I^{2}$} & 0.000 & 0.001 & 0.003 & -0.000 & -0.000 & -0.000 & -0.000 & -0.000 & 0.003 \\
\hline & {$[0.092]$} & {$[0.084]$} & [0.117] & {$[-0.036]$} & {$[-0.046]$} & {$[-0.010]$} & {$[-0.056]$} & {$[-0.026]$} & {$[0.074]$} \\
\hline & $(0.000)$ & $(0.001)$ & $(0.002)$ & $(0.000)$ & $(0.001)$ & $(0.002)$ & $(0.001)$ & $(0.002)$ & $(0.004)$ \\
\hline \multirow[t]{3}{*}{ Inventory } & $0.000 * * *$ & $0.000 * * *$ & $0.000 * * *$ & $0.000 * * *$ & $0.000 * * *$ & $0.000 * * *$ & $0.000 * * *$ & $0.000 * * *$ & $0.000 * * *$ \\
\hline & [0.627] & {$[0.676]$} & {$[0.676]$} & {$[0.582]$} & {$[0.696]$} & {$[0.742]$} & {$[0.468]$} & {$[0.564]$} & {$[0.723]$} \\
\hline & $(0.000)$ & $(0.000)$ & $(0.0000)$ & $(0.000)$ & $(0.000)$ & $(0.000)$ & $(0.000)$ & $(0.000)$ & $(0.000)$ \\
\hline \multirow[t]{3}{*}{ Inventory ${ }^{2}$} & $0.000 * * *$ & $-0.000 * * *$ & $0.000 * * *$ & $-0.000 * * *$ & $-0.000 * * *$ & $-0.000 * *$ & 0.000 & -0.000 & 0.000 \\
\hline & {$[-0.232]$} & {$[-0.223]$} & {$[-0.182]$} & {$[-0.281]$} & {$[-0.263]$} & {$[-0.161]$} & {$[0.020]$} & {$[-0.028]$} & {$[0.060]$} \\
\hline & $(0.000)$ & $(0.000)$ & $(0.000)$ & $(0.000)$ & $(0.000)$ & $(0.000)$ & $(0.000)$ & $(0.000)$ & $(0.000)$ \\
\hline \multirow[t]{3}{*}{ Interact } & $0.000 * *$ & $0.000 * *$ & $0.000 * * *$ & $0.000^{*}$ & $0.000 * *$ & $0.000 * * *$ & 0.000 & 0.000 & $0.000 * * *$ \\
\hline & {$[0.158]$} & {$[0.145]$} & {$[0.172]$} & {$[0.132]$} & {$[0.182]$} & {$[0.258]$} & {$[0.042]$} & {$[0.106]$} & {$[0.198]$} \\
\hline & $(0.000)$ & $(0.000)$ & $(0.000)$ & $(0.000)$ & $(0.000)$ & $(0.000)$ & $(0.000)$ & $(0.000)$ & $(0.000)$ \\
\hline \multicolumn{10}{|l|}{ Joint significance $F$ tests } \\
\hline$K C F S I, K C F S I^{2}$ & $6.243 * * *$ & $8.718 * * *$ & $12.200 * * *$ & 0.260 & 0.601 & 1.976 & $2.586^{*}$ & $7.451 * * *$ & $11.350 * * *$ \\
\hline Inventory, Inventory ${ }^{2}$ & $38.570 * * *$ & $45.802 * * *$ & $46.596 * * *$ & $20.961 * * *$ & $30.326 * * *$ & $37.114 * * *$ & $25.158 * * *$ & $32.517 * * *$ & $101.020 * * *$ \\
\hline KCFSI, KCFSI ${ }^{2}$, Interact & $6.518 * * *$ & $8.858 * * *$ & $14.296 * * *$ & $2.300 *$ & $3.203 * *$ & $7.526 * * *$ & 1.837 & $5.450 * * *$ & $8.841 * * *$ \\
\hline Inventory, Inventory ${ }^{2}$, Interact & $28.524 * * *$ & $33.354 * * *$ & $31.358 * * *$ & $13.980 * * *$ & $21.143 * * *$ & $26.100 * * *$ & $17.518 * * *$ & $21.681 * * *$ & $69.047 * * *$ \\
\hline$R^{2}$ & 0.454 & 0.498498 & 0.524 & 0.311 & 0.452 & 0.560 & 0.230 & 0.351 & 0.603 \\
\hline$F$-statistic & $48.911 * * *$ & $58.250 * * *$ & $64.698 * * *$ & $26.466 * * *$ & $48.4433 * * *$ & $73.661 * * *$ & $17.507 * * *$ & $31.861 * * *$ & $89.662 * * *$ \\
\hline
\end{tabular}


Table 4b. Nonlinear regression results for the full sample using VIX

\begin{tabular}{|c|c|c|c|c|c|c|c|c|c|}
\hline \multirow[b]{2}{*}{ Explanatory variables } & \multicolumn{3}{|c|}{ Crude oil } & \multicolumn{3}{|c|}{ heating oil } & \multicolumn{3}{|c|}{ Natural gas } \\
\hline & $i a b_{2}$ & $i a b_{4}$ & $i a b_{12}$ & $i a b_{2}$ & $i a b_{4}$ & $i a b_{12}$ & $i a b_{2}$ & $i a b_{4}$ & $i a b_{12}$ \\
\hline \multirow[t]{2}{*}{ Intercept } & 0.002 & 0.005 & 0.008 & $0.004 * *$ & $0.008 * *$ & 0.006 & -0.001 & -0.000 & -0.016 \\
\hline & $(0.000)$ & $(0.004)$ & $(0.011)$ & $(0.002)$ & $(0.004)$ & $(0.009)$ & $(0.003)$ & $(0.000)$ & $(0.014)$ \\
\hline \multirow[t]{3}{*}{$V I X$} & 0.000 & 0.000 & $0.002 *$ & -0.000 & 0.000 & 0.001 & 0.000 & 0.000 & $0.003^{*}$ \\
\hline & {$[0.151]$} & {$[0.142]$} & {$[0.143]$} & {$[-0.032]$} & [0.019] & {$[0.104]$} & {$[0.006]$} & {$[0.038]$} & {$[0.157]$} \\
\hline & $(0.000)$ & $(0.005)$ & $(0.001)$ & $(0.000)$ & $(0.000)$ & $(0.001)$ & $(0.000)$ & $(0.001)$ & $(0.002)$ \\
\hline \multirow[t]{3}{*}{$V I X^{2}$} & 0.000 & 0.000 & $0.000 * *$ & 0.000 & 0.000 & 0.000 & 0.000 & 0.000 & 0.000 \\
\hline & {$[0.103]$} & {$[0.108]$} & {$[0.141]$} & {$[0.096]$} & {$[0.085]$} & {$[0.094]$} & {$[0.024]$} & {$[0.036]$} & {$[0.065]$} \\
\hline & $(0.000)$ & $(0.000)$ & $(0.000)$ & $(0.000)$ & $(0.000)$ & $(0.000)$ & $(0.000)$ & $(0.000)$ & $(0.000)$ \\
\hline \multirow{3}{*}{ Inventory } & $0.000 * * *$ & $0.000 * * *$ & $0.000 * * *$ & $0.000 * * *$ & $0.000 * * *$ & $0.000 *$ & $0.000 * * *$ & $0.000 * * *$ & $0.000 * * *$ \\
\hline & {$[0.631]$} & [0.677] & {$[0.677]$} & {$[0.572]$} & {$[0.686]$} & {$[0.735]$} & {$[0.481]$} & {$[0.574]$} & {$[0.732]$} \\
\hline & $(0.000)$ & $(0.000)$ & $(0.000)$ & $(0.000)$ & $(0.000)$ & $(0.000)$ & $(0.000)$ & $(0.000)$ & $(0.000)$ \\
\hline \multirow[t]{3}{*}{ Inventory ${ }^{2}$} & $-0.000 * * *$ & $-0.000 * * *$ & $-0.000 * * *$ & $-0.000 * *$ & $-0.000 * * *$ & $-0.000 * * *$ & 0.000 & -0.000 & $0.000 * *$ \\
\hline & {$[-0.221]$} & {$[-0.207]$} & {$[-0.165]$} & {$[-0.260]$} & {$[-0.235]$} & {$[-0.134]$} & {$[0.030]$} & {$[-0.007]$} & {$[0.096]$} \\
\hline & $(0.000)$ & $(0.000)$ & $(0.000)$ & $(0.000)$ & $(0.000)$ & $(0.000)$ & $(0.000)$ & $(0.000)$ & $(0.000)$ \\
\hline \multirow[t]{3}{*}{ Interact } & $0.000 * *$ & $0.000 * * *$ & $0.000 * * *$ & 0.000 & $0.000 * * *$ & $0.000 * * *$ & 0.000 & 0.000 & $0.000 *$ \\
\hline & {$[0.160]$} & [0.164] & [0.177] & {$[0.123]$} & {$[0.176]$} & {$[0.231]$} & {$[0.054]$} & [0.064] & {$[0.105]$} \\
\hline & $(0.000)$ & $(0.000)$ & $(0.000)$ & $(0.000)$ & $(0.000)$ & $(0.000)$ & $(0.000)$ & $(0.000)$ & $(0.000)$ \\
\hline \multicolumn{10}{|l|}{ Joint significance $F$ tests } \\
\hline$V I X, V I X^{2}$ & $5.720 * * *$ & $8.911 * * *$ & $14.722 * * *$ & $3.420 * *$ & $5.161 * * *$ & $15.548 * * *$ & 0.545 & 2.098 & $4.279 * *$ \\
\hline Inventory, Inventory ${ }^{2}$ & $37.150 * * *$ & $8.293 * * *$ & $17.111 * * *$ & $22.011 * * *$ & $31.948 * * *$ & $37.727 * * *$ & $26.204 * * *$ & $29.484 * * *$ & $73.765 * * *$ \\
\hline$V I X, V I X^{2}$, Interact & $4.863 * * *$ & $46.615^{* * *}$ & $49.060 * * *$ & $4.220 * * *$ & $7.070 * * *$ & $24.714 * * *$ & 0.580 & 1.641 & $2.863 * *$ \\
\hline Inventory, Inventory ${ }^{2}$, Interact & $31.217 * * *$ & $38.987 * * *$ & $36.180 * * *$ & $14.825 * * *$ & $23.565 * * *$ & $30.891 * * *$ & $18.930 * * *$ & $19.727 * * *$ & $51.048 * * *$ \\
\hline$R^{2}$ & 0.435 & 0.487 & 0.515 & 0.321 & 0.462 & 0.554 & 0.225 & 0.336 & 0.55 \\
\hline$F$-statistic & $44.977 * * *$ & $55.605 * * *$ & $62.188 * * *$ & $27.721 * * *$ & $50.300 * * *$ & $71.581 * * *$ & $17.016 * * *$ & $29.734 * * *$ & $71.787 * * *$ \\
\hline
\end{tabular}




\section{Appendix 5. Time varying parameter estimations using KCFSI and VIX}

These graphs report the results from estimating equation 6 in the main text using the monthly de-trended and de-seasonalized data. The dependent variable is the 12-month interest-adjusted basis and the explanatory variables are the Federal Reserve Bank of Kansas City Financial Stress Index (KCFSI) and inventory reported in Figures 1a-1c, and VIX and inventory reported in Figures 2a-2c. The graphs visualize the evolution of the time varying parameters $\beta_{j}=\left(\beta_{j 0}, \ldots, \beta_{j T}\right), \mathrm{j}=1,2,3$ (including intercept that is not reported) over time $\mathrm{t}=0, \ldots, \mathrm{T}$. The median is displayed as a black line, and the grey shaded areas indicate the pointwise $90 \%$ to the $1 \%$ posterior credit intervals.

\section{Figures 1a-1c. KCFSI and inventory}
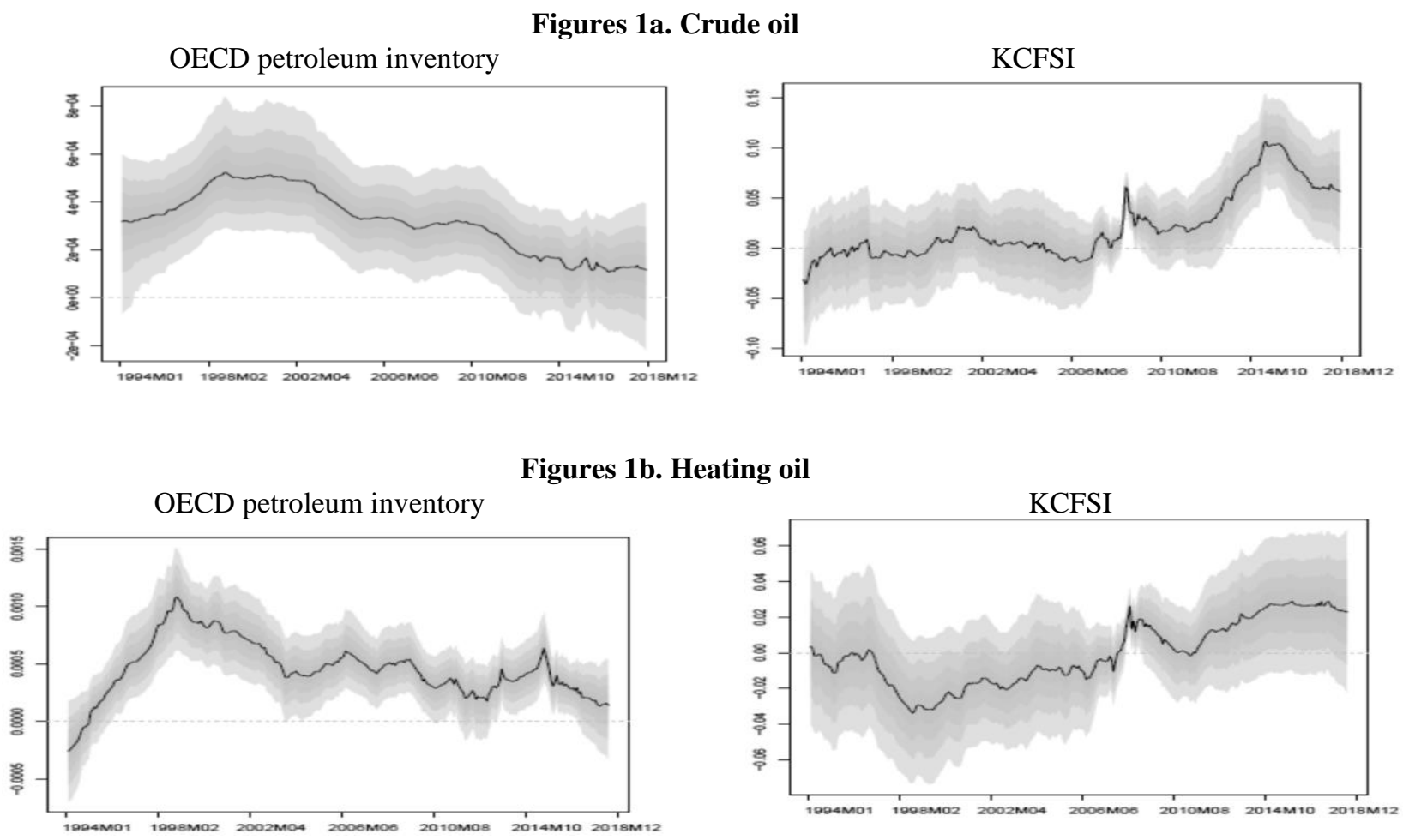

KCFSI

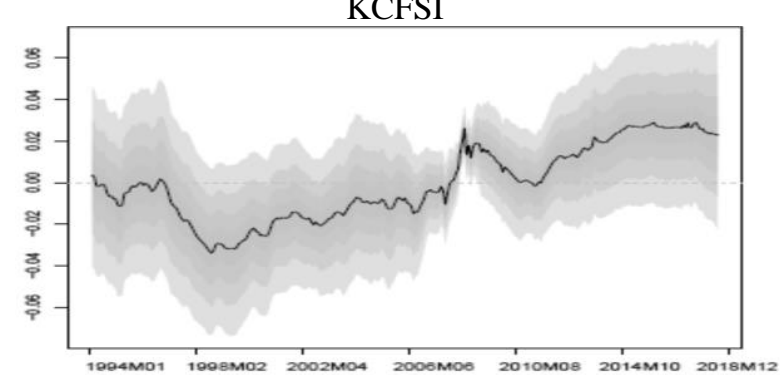

Figures 1c. Natural gas

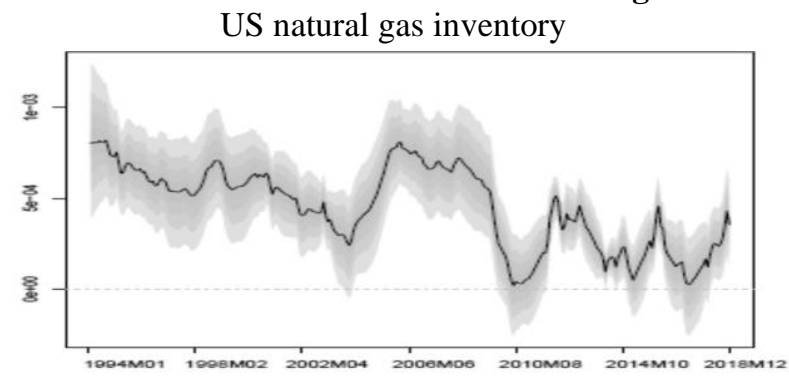

KCFSI

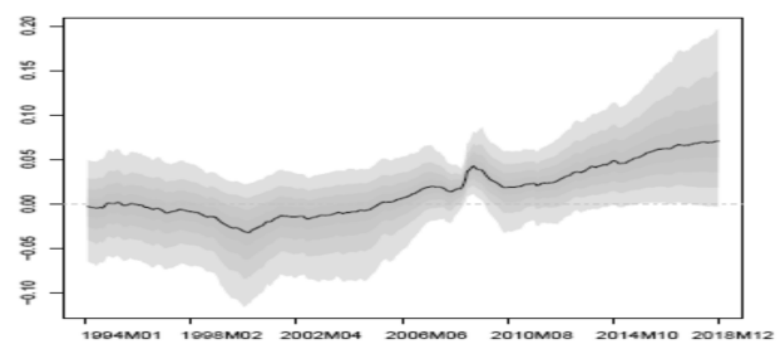


Figures 2a-2c. VIX and inventory

Figures 2a. Crude oil

US natural gas inventory

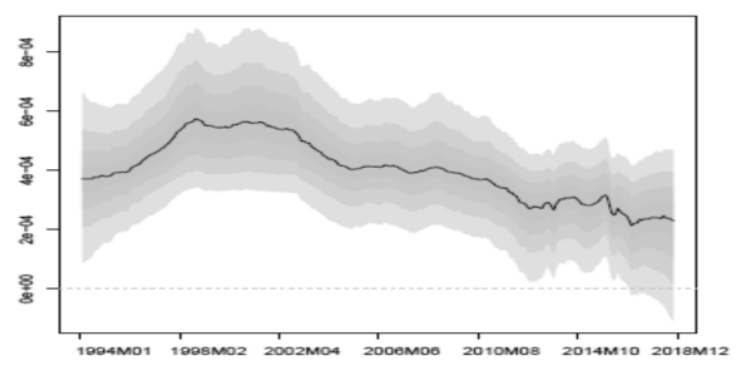

Figures 2b. Heating oil

US natural gas inventory

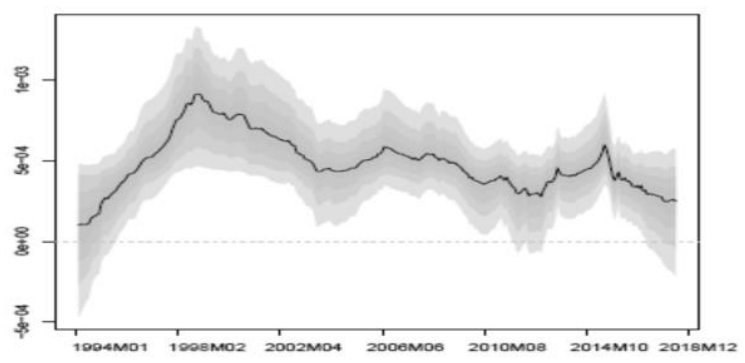

Figures 2c. Natural gas

US natural gas inventory

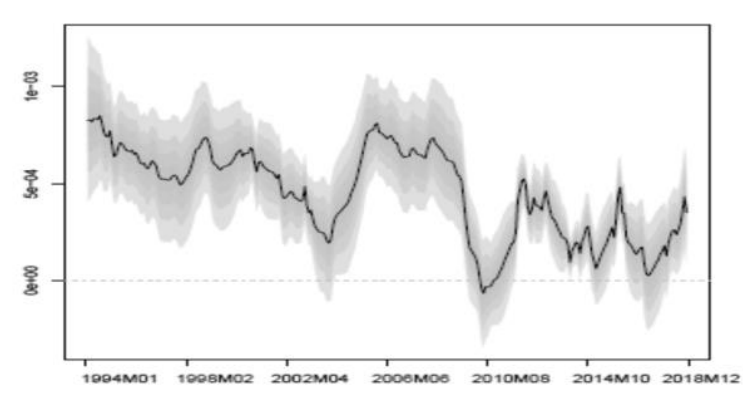

VIX

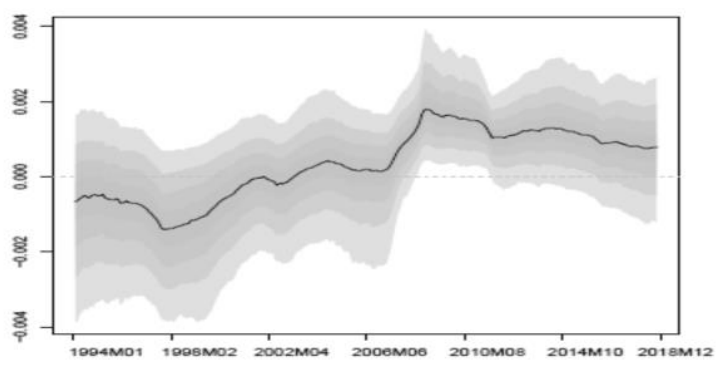

VIX

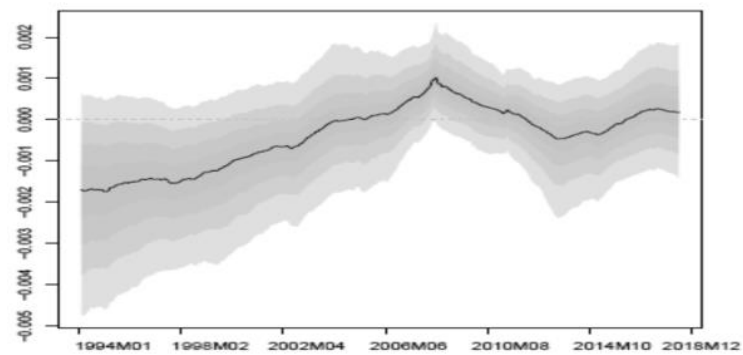

VIX

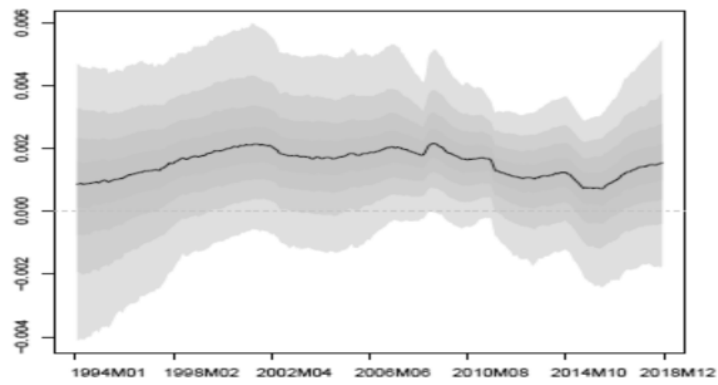




\section{REFERENCES}

Bitto, A., Friuhwirth-Schnatter, S. (2019). "Achieving shrinkage in a time-varying parameter model framework." Journal of Econometrics 210: 75-97.

Hakkio, C.S., Keeton, W.R. (2009). "Financial stress: what is it, how can it be measured, and why does it matter?" Economic Review 94: 5-50. 


\title{
Financial Stress and Basis in Energy Markets
}

\author{
Niaz Bashiri Behmiri $^{\mathrm{a}^{1}}$, Maryam Ahmadi ${ }^{\mathrm{b}}$, Juha-Pekka Junttila ${ }^{\mathrm{c}}$, Matteo Manera ${ }^{\mathrm{d}}$
}

a University of Stavanger, UiS Business School, Norway, b University of Milan-Bicocca, Italy, c University of Jyväskylä School of Business and Economics, Finland, dUniversity of Milan-Bicocca and Fondazione Eni Enrico Mattei (FEEM), Italy

\section{Executive summary}

Increased financialization of commodity markets developed the association between financial and commodity markets. Therefore, besides the physical inventories, the changes in financial market conditions became an important influential factor on commodity futures prices. In this study, we suspect that the conventional inventory-based models, only measuring the relationship between the commodities basis and inventory under the theory of storage, are not sufficient to explain and predict the changes in the spread between spot and futures prices, the so-called basis. The goal of this study is to understand the relationship between physical inventory, the US financial stress and the basis in the crude oil, heating oil and natural gas markets before and after increasing commodity financialization.

We examine the role of stress in the US financial markets on the energy commodities interest-adjusted basis during the time span from 1994 to 2018. We find that, only after the 2008 financial crisis, there are evidences for a positive effect from the increasing level of financial stress on the energy market commodities interest-adjusted bases. The effect of inventory remains positive during the whole time period; however, this positive effect gradually declines over time. Hence, after the 2008 collapse, the conventional inventory based models do not fully explain the energy market commodities bases. These results can be due to higher participation of financial investors, specifically hedge funds in commodity futures markets. Moreover, the association between the energy commodities interest-adjusted bases with the changes in financial stress is nonlinear, as the bases reactions to the financial stress are higher in the high financial stress periods. This is more profound in crude oil market than heating oil and natural gas. Moreover, the reactions of the energy commodities interest-adjusted bases to the changes in the level of inventory is nonlinear, as the reactions is lower when the level of inventory is high confirming the theory of storage. Finally, there is an interaction effect between inventory and financial stress, which shows that the strength of the effect of inventory (financial stress) on the energy commodities adjusted-basis depends on the level of financial stress (inventory).

Therefore, after the 2008 crisis, inventories have not been the only driver behind the changes in energy commodities markets bases, as with the growing financial liberalization of commodities, financial market conditions have become an important factor in explaining the behavior of bases in energy markets. This is more evident during higher turbulence in the financial markets. Therefore, variations of the spread between spot and futures prices are not only a signal of scarcity or abundance of the commodities in question. These results are useful for all the energy markets participants, the financial market traders, refiners and other energy users who consider the energy bases variations when making their decisions. In addition, the results are important to policy makers for the part of financial market related shock effects on the real economy, i.e., the energy commodity markets in this case.

Keywords: Energy market bases, financial stress, inventories JEL Classification: C51, G12, Q02, Q

\footnotetext{
${ }^{1}$ Corresponding author, email address: bashiri.niaz@gmail.com
} 